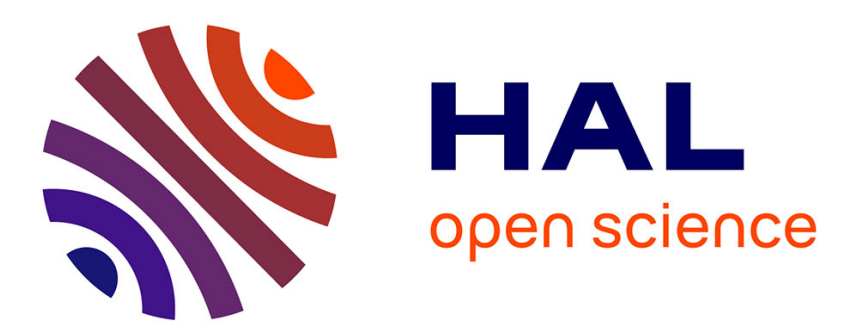

\title{
Co-digestion of solid waste: Towards a simple model to predict methane production
}

Mokhles Kouas, Michel Torrijos, Sabine Schmitz, Philippe Sousbie, Sami

Sayadi, Jérôme Harmand

\section{- To cite this version:}

Mokhles Kouas, Michel Torrijos, Sabine Schmitz, Philippe Sousbie, Sami Sayadi, et al.. Co-digestion of solid waste: Towards a simple model to predict methane production. Bioresource Technology, 2018, 254, pp.40-49. 10.1016/j.biortech.2018.01.055 . hal-02623301

\section{HAL Id: hal-02623301 https://hal.inrae.fr/hal-02623301}

Submitted on 26 May 2020

HAL is a multi-disciplinary open access archive for the deposit and dissemination of scientific research documents, whether they are published or not. The documents may come from teaching and research institutions in France or abroad, or from public or private research centers.
L'archive ouverte pluridisciplinaire HAL, est destinée au dépôt et à la diffusion de documents scientifiques de niveau recherche, publiés ou non, émanant des établissements d'enseignement et de recherche français ou étrangers, des laboratoires publics ou privés. 


\section{Accepted Manuscript}

Co-digestion of solid waste: Towards a simple model to predict methane production

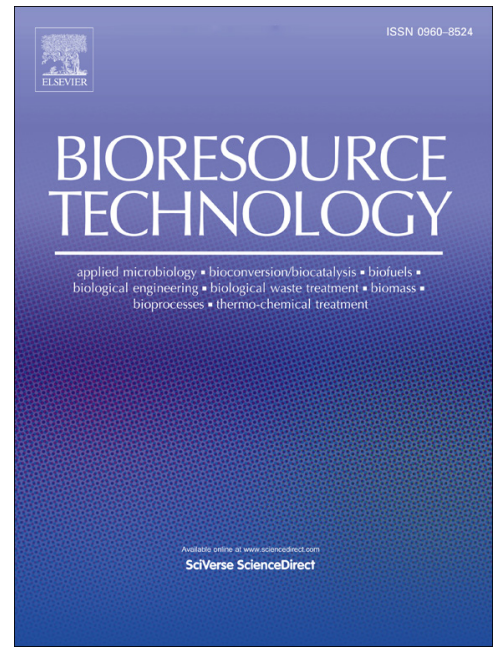

Mokhles Kouas, Michel Torrijos, Sabine Schmitz, Philippe Sousbie, Sami Sayadi, Jérôme Harmand

PII:

DOI:

Reference:

To appear in:

Received Date:

Revised Date:

Accepted Date:
S0960-8524(18)30068-3

https://doi.org/10.1016/j.biortech.2018.01.055

BITE 19412

Bioresource Technology

12 November 2017

8 January 2018

10 January 2018

Please cite this article as: Kouas, M., Torrijos, M., Schmitz, S., Sousbie, P., Sayadi, S., Harmand, J., Co-digestion of solid waste: Towards a simple model to predict methane production, Bioresource Technology (2018), doi: https:// doi.org/10.1016/j.biortech.2018.01.055

This is a PDF file of an unedited manuscript that has been accepted for publication. As a service to our customers we are providing this early version of the manuscript. The manuscript will undergo copyediting, typesetting, and review of the resulting proof before it is published in its final form. Please note that during the production process errors may be discovered which could affect the content, and all legal disclaimers that apply to the journal pertain. 


\title{
Co-digestion of solid waste: Towards a simple model to predict methane
} production

Mokhles Kouas $^{\mathrm{a}, \mathrm{b}}$, Michel Torrijos ${ }^{\mathrm{a}}$, Sabine Schmitz ${ }^{\mathrm{a}}$, Philippe Sousbie ${ }^{\mathrm{a}}$, Sami Sayadi ${ }^{\mathrm{b}}$, Jérôme Harmand

${ }^{\text {a }}$ LBE, INRA, Univ Montpellier, 102 avenue des Etangs, 11100, Narbonne, France

${ }^{\mathrm{b}}$ Laboratory of Environmental Bioprocesses, Centre of Biotechnology of Sfax, University of Sfax, Sidi Mansour Road Km 6, PO Box «1177», 3018 Sfax,

\section{Tunisia}

* Corresponding Author: e-mail: michel.torrijos@inra.fr; tel. (+33) 4684251 85;

\begin{abstract}
Modeling methane production is a key issue for solid waste co-digestion. Here, the effect of a step-wise increase in the organic loading rate (OLR) on reactor performance was investigated, and four new models were evaluated to predict methane yields using data acquired in batch mode. Four co-digestion experiments of mixtures of 2 solid substrates were conducted in semi-continuous mode. Experimental methane yields were always higher than the BMP values of mixtures calculated from the BMP of each substrate, highlighting the importance of endogenous production (methane produced from auto-degradation of microbial community and generated solids). The experimental methane productions under increasing OLRs corresponded well to the modeled data using the model with constant endogenous production and kinetics identified at $80 \%$ from total batch time. This model provides a simple and useful tool for technical design consultancies and plant operators to optimize the co-digestion and the choice of the OLRs.
\end{abstract}


Keywords: anaerobic co-digestion, solid waste, organic loading rate, kinetic modeling, fractionation

\section{Introduction}

In recent years, the interest for renewable energies has grown, driven by the increasing concern about global warming, energy security, resources recovery and, also, the high output of organic solid waste and issues related to their disposal. Therefore, the need has arisen to develop and optimize technologies facilitating the proper treatment of waste while at the same time producing renewable energy. Anaerobic digestion (AD) is an interesting option as it represents a well-developed and robust technology used for managing organic waste, reducing its volume while producing biogas composed mainly of $\mathrm{CH}_{4}$ and $\mathrm{CO}_{2}$. Anaerobic co-digestion (AcoD) is increasingly being applied for several kinds of solid waste. The term AcoD refers to the simultaneous treatment of two or more organic substrates (Mata-alvarez et al., 2011). AcoD offers ecological, technological and economic advantages such as enhanced digester performance compared to mono-digestion (Khalid et al., 2011), dilution of inhibitors, improvement of the balance of nutrients (Gannoun et al., 2007) and of the $\mathrm{C} / \mathrm{N}$ ratio. Consequently, many studies have been carried out to investigate the impact of the co-digestion of a variety of substrates including fruit and vegetable waste (FVW), waste activated sludge

(WAS), primary sludge, agricultural waste, manure, energy crops and food waste (Mata-alvarez et al., 2011). Process performance and its stability are essential criteria for the efficient operation of a digester and the avoidance of process failure. To avoid process instability, the organic loading rate (OLR) in particular, is one of the most important factors which must be optimized and carefully chosen when designing a 
plant. Several studies have investigated the effect of increasing the OLR in continuous mode (Agyeman and Tao, 2014; Ganesh et al., 2013; Zhang and Jahng, 2012). Ganesh et al. (2013) studied the impact of increasing OLRs (1.5-7.5 $\left.\mathrm{kgVSm}^{-3} \mathrm{~d}^{-1}\right)$ in a codigestion reactor fed with FWV, grass and cow manure. The authors reported increasing volumetric methane production with a rise in the OLR but a drop of $20 \%$ in the methane yield (MY) for the higher applied OLR compared to the lower one. Comino et al. (2010) investigated the co-digestion of cow manure and crop silage in a pilot biogas plant run with increasing OLRs. The reported MYs were 237, 249 and $61 \mathrm{~L} \mathrm{CH}_{4} \mathrm{~kg} \mathrm{VS}^{-1}$ at, respectively, 4.45, 5.15 and $7.78 \mathrm{~g} \mathrm{VS} \mathrm{L}^{-1} \mathrm{~d}^{-1}$ and process breakdown was shown at the highest applied OLR. Co-digestion of the separated solid fraction of pig manure with dried grass silage under increasing OLRs, from 1 to $3 \mathrm{kgm}^{3} \mathrm{~d}^{-1}$, was reported by Xie et al. (2012). The results showed a rise in the volumetric methane production of $88 \%$ while the MY decreased by an average of 38\%. These results show that the effect of the OLR on process performance i.e. the OLR from which the process starts being unstable, depends on the characteristics and degradability of the co-digested substrates.

Consequently, it is absolutely necessary to take into account these parameters when designing an anaerobic digester.

Modeling represents an effective way to optimize AcoD process design and operation, monitor anaerobic digesters and better formalize available knowledge.

Furthermore, models improve the understanding of the system, facilitate the formulation and validation of certain hypotheses and thus reduce costs, the risk of failure and process operating time (Donoso-Bravo et al., 2011) by recourse to a variety of approaches for estimating parameters and validating models. In a recent review, Xie et al. (2016) defined 5 categories for AD and AcoD models. Anaerobic Digestion Model 1 
(ADM1) is the most widely applied model in the field of $\mathrm{AD}$ and AcoD research; in the

15 years since its development, extensions and modifications have been introduced in order to take into account inhibitions coming from co-substrates and intermediates (Garcia-Gen et al., 2013), to include Volatil Fatty Acids (VFA) inhibition (Boubaker and Ridha, 2008), degradation of contaminants and, recently, phosphorus, sulfur and iron physico-chemical and biological reactions (Flores-Alsina et al., 2016). On the other hand, certain limitations of ADM1 have been acknowledged in the literature, notably the complexity of its implementation. Furthermore, ADM1 needs detailed input variables for each processed substrate; these are not always available. Hence, substrate characterization is a critical issue for process description: it reduces its effectiveness for predicting reactor performance at both industrial and lab scale due to the time taken by the analyses for substrate characterization (Astals et al., 2013; Charnier et al., 2017). Clearly, there was a need for setting up a substrate database, such as that published by Kouas et al. (2017) for 50 solid residues; it includes the Biochemical Methane Potential (BMP) and degradation kinetics. In addition, developing simpler modeling approaches to predict digester performance is especially needed in the case of the AcoD of solid wastes in order to reduce the complexity of the previous models and make it simpler to use in respect of structural properties, simulation and interpretation.

The objectives of the present work are: firstly, to study the co-digestion of mixtures of two substrates with different characteristics in semi-continuous digesters operated with an increasing OLR; secondly, to investigate the possibility of predicting the volume of methane produced from the co-digestion reactors at different OLRs using a simple modeling approach based on individual substrate characterization in batch mode (BMPs and kinetic fractionation). These two objectives were achieved by: i) the 
individual characterization of the substrates used in successive batches to assess their BMP and to identify the fractionation of their organic matter and degradation kinetics using a simple model; ii) the study of the performance and stability of four semicontinuous reactors fed with different mixtures of two substrates under step-wise increases in the OLR; iii) the comparison of several simple models based on data acquired in batch mode in order to predict the methane production from each of the 4 co-digesters.

The final objective is to develop a simple model in order to propose a straightforward, useful tool to design consultancies and plant operators for the optimization of any mixture of substrates and for the design of reactors (choice of the OLR to be used and prediction of methane production).

\section{Materials and methods}

\subsection{Substrates}

Six different solid substrates were used in this study: carrot, cabbage, tomato, bread (French baguette), beef meat at 5\% fat and manure (a mix of cow dung and straw). The substrates were crushed, characterized by measuring the concentrations of total solids (TS) and volatile solids (VS), see Table 1 , then stored at $-20^{\circ} \mathrm{C}$ before use.

\subsection{Reactors}

Batch and semi-continuous experiments were carried out in double-walled reactors of $6 \mathrm{~L}$ effective volume, maintained at $37^{\circ} \mathrm{C}$ by a regulated water bath. Mixing in reactors was done by a system of magnetic stirring for batch experiments but by mechanical stirring for semi-continuous experiments as the total suspended solids (TSS) 
concentrations could exceed the threshold for agitation by magnetic stirring (30 g TSS

$\mathrm{L}^{-1}$ ). The biogas production was measured on line by Milligascounter MGC-1 V3.1 flow meters (Ritter gas meters) fitted with a 4-20mA output. The Odin Silex software developed at the INRA laboratory was used to acquire the data.

\subsection{Inoculation of the reactors}

The reactors, both in successive batches and semi-continuous operation, were seeded with anaerobic sludge taken from an industrial-scale anaerobic UASB reactor treating the effluents from a sugar refinery. $800 \mathrm{~g}$ of drained granules were added to each reactor and then tap water was added to $6 \mathrm{~L}$ in order to obtain a volatile suspended solids (VSS) concentration in the range of $12-15 \mathrm{gVSS} \mathrm{L}^{-1}$. The reactors were kept under agitation for 4 days to break up the granules. To check the activity of the sludge, after seeding and before starting the addition of waste, the reactors were fed twice with $2 \mathrm{~mL}$ of ethanol followed by 3 times with $5 \mathrm{~mL}$ of ethanol as a sole source of carbon and energy.

\subsection{Operating conditions}

Three reactors were operated in batch mode in order to characterize the six substrates individually in successive batches in accordance with the protocol developed at the INRA laboratory (Kouas et al., 2017).

Four reactors were operated in semi-continuous mode with one feeding per day each of five week days and no feeding on the weekends. Each reactor was fed with a different mixture of two substrates and run for several months at increasingly higher organic loading rates (OLRs). The four different mixtures used were: Carrot and Bread $(\mathrm{C}+\mathrm{B})$, Carrot and Cow Manure $(\mathrm{C}+\mathrm{CM})$, Carrot and Cabbage $(\mathrm{C}+\mathrm{Cab})$, Tomato and Beef Meat $(\mathrm{T}+\mathrm{BM})$. In terms of $\mathrm{VS}_{\mathrm{added}}$, the first three mixtures were made with $50 \%$ of 
each substrate; for $\mathrm{T}+\mathrm{BM}$, the mix was made with $70 \%$ of tomato and $30 \%$ of $\mathrm{BM}$ in order to take into account possible inhibition caused by the high Nitrogen concentration in $\mathrm{BM}$. The reactors fed with $\mathrm{C}+\mathrm{B}$ and $\mathrm{C}+\mathrm{CM}$ were operated at OLRs of $0.5,1,1.5$, $1.75,2,2.25,2.5,2.75$ and $3 \mathrm{gVS} \mathrm{L}^{-1} \mathrm{~d}^{-1}$; the reactor fed with $\mathrm{C}+\mathrm{Cab}$ at OLRs of $0.5,1$, $1.5,1.75,2,2.25$ and $2.5 \mathrm{gVS} \mathrm{L}^{-1} \mathrm{~d}^{-1}$; and the reactor fed with $\mathrm{T}+\mathrm{BM}$ at OLRs of $1,1.5$, 2 and $2.5 \mathrm{gVS} \mathrm{L}^{-1} \mathrm{~d}^{-1}$. Reactors were operated and monitored for 32 weeks for $\mathrm{C}+\mathrm{B}$ and $\mathrm{C}+\mathrm{CM}, 28$ weeks for $\mathrm{C}+\mathrm{Cab}$ and 16 weeks for $\mathrm{T}+\mathrm{BM}$. Each OLR was applied for 3 to 4 weeks.

\subsection{Kinetic fractionation of the substrates}

The kinetic fractionation of the substrates was done in accordance with the protocol for successive batches developed at the INRA laboratory, as described by Kouas et al. (2017). Using the net methane production curve obtained in batch after removing the endogenous production (representing the methane produced from auto-degradation of microbial community and by the degradation of generated solids), this protocol makes it possible to measure the BMP of the whole substrate and to fractionate its biodegradable organic matter into 3 sub-fractions, or compartments, with different degradation kinetics: rapidly, moderately and slowly biodegradable sub-fractions. The degradation rate of each sub-fraction is assumed to be constant and to follow a zero order kinetic $\left(d S_{i} / d t=-k i\right)$. For each compartment $i$, two parameters were identified: the percentage of fraction $i\left(\% S_{i}(0)\right)$ in the whole substrate and the degradation rate $\left(k_{i}\right)$. As the identification of a parameter was made from the evolution of methane production over time, the quantity of substrate is expressed in $\mathrm{mL}_{\text {of }} \mathrm{CH}_{4}$ which can be produced from the organic matter added. As a consequence, $S(0)$ represents the maximum volume of 
methane which can be produced from the degradation of all the organic matter added and $S_{i}(0)$ represents the volume of methane which can be produced from the degradation of sub-fraction $i$. $k_{i}$, expressed in $\mathrm{mLCH}_{4}$ per hour, represents the rate of methane production from the degradation of the sub-fraction $i$ while $-k_{i}$ represents the subfraction degradation rate.

\subsection{Modeling based on the kinetic fractionation of the substrates}

The fractionation of the organic matter into three sub-fractions with different degradation kinetics was used for the forecast of methane production using the methodology described in Kouas et al. (2017). ( $\left.\operatorname{Vol}_{i}(t)\right)$, the methane production from each sub-fraction at time $t$ was calculated according to Eq. (1):

$\operatorname{Vol}_{i}(t)=\min \left(k_{i} * t, S_{i}(0)\right)$ with $i \in[1,2,3]$

The total volume of methane produced at time $t$ was:

$\operatorname{Vol}(t)=\sum \operatorname{Vol}_{i}(t)$ with $i \in[1,2,3]$

The residual quantity of each sub-fraction at time $t$ can be written as:

$S_{i}(t)=\max \left(S_{i}(0)-k_{i} * t, 0\right)$ with $i \in[1,2,3]$

The total quantity of substrate left at time $t$ was calculated as:

$S(t)=\sum S_{i}(t) \quad$ with $i \in[1,2,3]$

\subsection{Modelling of AcoD}

To simulate methane production from co-digestion reactors fed with two substrates, each of the six sub-fractions of the substrates was considered independently. Methane production over time from each sub-fraction was simulated according to Eq. (1) using data acquired in batch mode (BMP and the fractionation of the organic matter $\left(k_{i}\right.$ and \% $\left.\left.S_{i}(0)\right)\right)$. As the reactors were operated in fed-batch mode with five feedings per week 
and two days without feeding, the simulation after the last feeding lasted for three days. If the organic matter of a sub-fraction was not fully eliminated before a new feeding, then the residual amount was added to the quantity fed into the reactor. Finally, the six methane productions from both mixed substrates (the first being fractionated as $S_{l}(0)$ to $S_{3}(0)$ and the second as $S_{4}(0)$ to $\left.S_{6}(0)\right)$ were added in accordance with Eq. (5):

$$
\operatorname{Vol}(t)=\sum_{j=1}^{j=5} \operatorname{VVol}_{i}(t) \quad i \in[1, . ., 6]
$$

with $j$ the number of feeding and $i$ the number of sub-fractions. Hereafter, when Eq. (5) is involved, additivity was assumed.

To evaluate the predictive capacities of the model, a maximum percentage of difference (DP) of $10 \%$ for the methane yield (MY) was fixed to judge the prediction as acceptable (Yazidi and Thanikal, 2016). Furthermore, the kinetic fitting between the experimental and the modeled weekly methane production curves was also investigated. The relative absolute error ( $\mathrm{rAE}$ ) was calculated using Eq. (6) to better assess the different modelling approaches. In this study, a maximum rAE of $20 \%$ was fixed to judge the kinetics prediction as acceptable and reasonable:

$$
(\mathrm{rAE})=\frac{\sum_{i=1}^{n}((|y \exp -y \bmod |) / y \exp )}{n}
$$

with $y_{\text {exp }}$ the experimental value of the methane produced, $y_{m o d}$ the modeled value of the methane produced and $n$ the number of experimental points.

\subsection{Analysis}

The soluble phase was separated from the solids in suspension by centrifugation using either a Beckman J2-MC or a Beckman Coulter. The conditions of centrifugation were $18000 \mathrm{rpm}$ for 20 minutes at $19^{\circ} \mathrm{C}$. The supernatant was used for determining the VFA concentration and the Chemical Oxygen Demand (COD) and the precipitate 
(pellet) was used for the measurement of TS and VS. VFA were analyzed using a Perkin Clarus 580 gas chromatograph (PerkinElmer® 181, 182 Waltham, USA) according to Cazier et al. (2015). Soluble COD was determined according to the micro-method for accurate and rapid measurement (Hach $0-1500 \mathrm{mgL}^{-1}$ vials). The various parameters such as $\mathrm{pH}$, TS and VS concentrations and total alkalinity were measured following standard methods, APHA (2005). Gas composition was measured using a Clarus 480 Gas Chromatograph (Perkin Elmer). The following gases were measured: $\mathrm{CO}_{2}, \mathrm{H}_{2} \mathrm{~S}, \mathrm{O}_{2}$, $\mathrm{N}_{2}$ and $\mathrm{CH}_{4}$ as described in Kouas et al. (2107).

\section{Results and discussion}

\subsection{Individual substrate characterization in successive batches}

Table 1 gives the results of the characterization for the six substrates. The BMP values were $70,295,305,309,341$ and $347 \mathrm{mLCH}_{4} \mathrm{gVS}^{-1}$ for, respectively, cow manure, bread, cabbage, carrot, beef meat and tomato. The evaluated BMPs were in coherence and comparable with other reported values (Ferrer et al., 2014; Gunaseelan, 2004; Raposo et al., 2011), more details in Kouas et al. (2107). Among vegetables, cabbage had a higher fraction of the most slowly-degradable fraction compared to carrot and tomato due to its lignocellulosic structure. Beef meat and bread, made up mainly of proteins or starch respectively, had a majority of the $S_{2}$ fraction. Cow manure had a very low BMP and more than $70 \%$ of its organic matter, rich in lignocellulosic and hemicellulosic compounds, had a very low degradation rate, thus suggesting an important previous aerobic degradation during storage at farm.

\subsection{Co-digestion in a semi-continuous reactor}

\subsubsection{Example of results with the mix of Carrot and Bread}


Fig. 1 presents an example of the results obtained with the reactor fed with carrot and bread $(\mathrm{C}+\mathrm{B})$. Fig. 1A shows that the reactor behaved quite well after each increase of the OLR. Indeed, the total volume of methane produced per week increased each time the OLR was raised. As indicated in materials and methods, each OLR was maintained for 3 or 4 weeks. Thus, taking into account the long HRTs, especially for the lowest OLRs, it was not possible to wait for 3 HRT for each condition applied. However, it is important to underline that VSS concentration in the reactor was fairly constant throughout the experiment, linked to the initial conditions chosen, at an average of $1.6 \pm 0.5 \%$ suggesting that the concentration of the microorganisms was fairly constant in the experimental conditions used.

From the weekly cumulative methane production, the methane productivity and the methane yield were calculated at all OLRs (Fig. 1B). The productivity of the digester increased proportionally to the increases in OLR and the methane yield was constant at $363 \pm 12 \mathrm{~mL} \mathrm{CH}_{4} \mathrm{gVS}^{-1}$ up to an OLR of about $1.75 \mathrm{gVS} \mathrm{L}^{-1} \mathrm{~d}^{-1}$. For higher OLRs, MY decreased slightly and, compared to the value at an OLR of $0.5 \mathrm{gVS} \mathrm{L}^{-1} \mathrm{~d}^{-1}, \mathrm{MY}$ decreased by $10 \%$ at an OLR of $2 \mathrm{gVS} \mathrm{L}^{-1} \mathrm{~d}^{-1}$ and $15 \%$ at an OLR of $3 \mathrm{gVS} \mathrm{L}^{-1} \mathrm{~d}^{-1}$. Fig. $1 \mathrm{C}$ presents the VFA concentration at the end of the week, that is to say 3 days after the last feeding, in relation to the OLR. For the higher OLRs, not all the acidified organic matter was eliminated which explains the slightly lower MYs observed. However, there was no impact of the accumulated VFA on $\mathrm{pH}$ which was around 7 throughout the experiment.

The Final methane production rate (FMPR) at the end of a week after more than 2 days without feeding (i.e. the slope of cumulative methane production curve during the 
last 12 hours of a week) provides important information on the microbial activity in the reactor. Fig. 1C shows that this parameter had slightly increasing values when the OLR was increased. Indeed, at $0.5 \mathrm{gVS} \mathrm{L}^{-1} \mathrm{~d}^{-1}$, the FMPR at the end of the week was very low $\left(7 \mathrm{mLCH}_{4} \mathrm{~h}^{-1}\right)$. The value of MPR found in all digesters at $0.5 \mathrm{gVS} \mathrm{L}^{-1} \mathrm{~d}^{-1}$ was close $\left(8.7 \pm 1.5 \mathrm{mLCH}_{4} \mathrm{~h}^{-1}\right)$ which suggests that all the organic matter added had been eliminated and the methane produced was linked essentially to the endogenous production (EP) only. For higher OLRs and up to $2.25 \mathrm{gVS} \mathrm{L}^{-1} \mathrm{~d}^{-1}$, the FMPR rose slowly indicating an increase in the final activity of the reactor compared to that at an OLR of $0.5 \mathrm{gVS} \mathrm{L}^{-1} \mathrm{~d}^{-1}$. A sudden increase was observed above an OLR of $2.25 \mathrm{gVS} \mathrm{L}^{-}$ ${ }^{1} \mathrm{~d}^{-1}$, indicating a strong microbial activity; this suggests that some of the added organic matter was still being degraded in particular VFA which had accumulated in the liquid phase (see Fig. 1C).

Soluble COD remained fairly constant up to the OLR of $2 \mathrm{gVS} \mathrm{L}^{-1} \mathrm{~d}^{-1}$ but then it increased rapidly to reach a concentration of $0.253 \mathrm{gL}^{-1}$ for the highest applied OLR of $3 \mathrm{gVS} \mathrm{L}^{-1} \mathrm{~d}^{-1}$. This fits with the accumulation of VFA.

\subsubsection{Results for the four mixtures}

The same data treatment was applied to the three other digesters fed with $\mathrm{C}+\mathrm{CM}$, $\mathrm{C}+\mathrm{Cab}$ and $\mathrm{T}+\mathrm{BM}$ in order to evaluate the performance of co-digestion at increasing OLRs via the weekly cumulative volume of methane produced, the methane productivity and the methane yield based on the quantity of substrate fed. Fig. 2 presents the evolution of methane productivity and methane yield as the OLRs rose in the four reactors. For a given OLR, methane productivity (MP) had different values for each mix, depending on the BMP of the substrates. Furthermore, for all reactors MP 
increased with OLR and the highest MP was always recorded for the highest OLR applied. The average MY for all OLRs were $241 \pm 27,343 \pm 22,382 \pm 18$ and $433 \pm 4$ $\mathrm{mLCH}_{4} \mathrm{gVS}^{-1}$, respectively, for $\mathrm{C}+\mathrm{CM}, \mathrm{C}+\mathrm{B}, \mathrm{C}+\mathrm{Cab}$ and $\mathrm{T}+\mathrm{BM}$. Two different behavior patterns were observed depending on the mixtures. For $\mathrm{T}+\mathrm{BM}$ and $\mathrm{C}+\mathrm{Cab}$, the MY was fairly constant at all OLRs. This result showed that the efficiency of organic matter removal was the same at whatever OLRs. For the other two mixtures, $\mathrm{C}+\mathrm{B}$ and $\mathrm{C}+\mathrm{CM}$, a slight decrease in the MY was observed as the OLR was increased. In fact, for both mixtures the MY was constant up to an OLR of $1.75 \mathrm{gVS} \mathrm{L}^{-1} \mathrm{~d}^{-1}$ but then started to decrease at higher OLRs. The decrease in the MY and the appearance of VFAs at the end of the week indicated that both reactors started to be slightly overloaded since all the added organic matter was not fully eliminated. It is a signal of imbalance between acidogenesis and methanogenesis. $\mathrm{pH}$ values in the reactor were around 7 for the mixtures of $\mathrm{C}+\mathrm{B}, \mathrm{A}+\mathrm{CM}$ and $\mathrm{C}+\mathrm{Cab}$ and between 7.5 and 8 for $\mathrm{T}+\mathrm{BM}$. This could have been due to high nitrogen concentration in BM. This result suggests the high buffering capacity of the digesters.

The FMPR during the last 12 hours of a week for the four mixtures at all OLRs is presented in Fig. 3. This final rate reflects the methane production linked to the EP (methane produced by the auto-degradation of the microbial community and by the degradation of generated solids) and by the degradation of the as-yet-non-degraded substrates. The average VSS concentrations during the experiments were, respectively, $1.6 \pm 0.5 \%, 2.3 \pm 0.4 \%, 2 \pm 0.23 \%, 2 \pm 0.33 \%$ for $\mathrm{C}+\mathrm{B}, \mathrm{C}+\mathrm{CM}, \mathrm{C}+\mathrm{Cab}$ and $\mathrm{T}+\mathrm{BM}$, respectively, indicating a fairly constant concentration of the microorganisms over time. For the lowest OLR of $0.5 \mathrm{gVS} \mathrm{L}^{-1} \mathrm{~d}^{-1}$, all the reactors had a very similar final production rate, at an average of $8.7 \pm 1.5 \mathrm{~mL} \mathrm{CH}_{4} \mathrm{~h}^{-1}$. At this low OLR, it was assumed 
that the added organic matter had been fully eliminated and the FMPR represents mostly the EP. For all digesters the FMPR rose with the increase in the OLR, indicating that the fraction of slowly-biodegradable matter still being eliminated increased for the higher OLRs. A sudden increase is shown above an OLR of $2.25 \mathrm{gVS} \mathrm{L}^{-1} \mathrm{~d}^{-1}$ for $\mathrm{C}+\mathrm{B}$ (see Fig. 1C) and C+CM concurrently with the appearance of a slight concentration of VFA. The strong microbial activity of the reactor suggests that some of the added organic matter was still being degraded. (FMPR values when there were VFAs were not involved in the calculation, see Supplementary material).

The results obtained for the four co-digestion reactors show that regardless of the OLR applied, MYs measured in fed-batch conditions were always higher than the BMP of the mixtures calculated from the addition of the BMP values of each substrate and the respective quantities of VS added. Indeed, MYs were in the range 378-312, 280-209, 417-366 and 438-428 $\mathrm{mLCH}_{4} \mathrm{gVS}^{-1}$ for, respectively, C+B, C+CM and C+Cab and T+BM while the calculated BMPs of the mixtures were 303, 190, 308 and 355, respectively. However, BMPs were calculated from the net methane production, i.e. after subtracting the endogenous methane production from the total methane production. Hence, in order to compare the BMP of the mixes in batch with the MY in fed-batch mode, it is necessary to evaluate the net methane production in fed-batch mode. For each mix, the endogenous production rate in the reactor was assessed at the lowest OLR applied (see Fig. 3) and during the last 12 hours of a week, i.e. during the third day following the last feeding. The low and very close final methane production rates at the lowest applied OLRs suggest that all the organic matter from the substrates was degraded, even for substrates with low degradation kinetics linked to the small quantity of organic matter added at such low OLRs. Hence, the final methane production rates 
were used to calculate endogenous methane production during a week with the hypothesis that it is constant over the whole week. The volume of methane produced by endogenous activity was subtracted from the total methane production in order to evaluate the "net" methane yield. For each mix, the calculated BMP was compared with the net MY at the lowest applied OLR. The differences were 3\%,11\%,2\% and $9 \%$ for, respectively, $\mathrm{C}+\mathrm{B}, \mathrm{C}+\mathrm{CM}, \mathrm{C}+\mathrm{Cab}$ and $\mathrm{T}+\mathrm{BM}$. The small differences observed between the predicted BMPs and the net experimental MYs shows that the modelling hypotheses were correct in the used operational conditions. Furthermore, the results also suggest that endogenous methane production can be assessed at low OLR $\left(\leq 1 \mathrm{gVS} \mathrm{L}^{-1} \mathrm{~d}^{-1}\right)$.

The results obtained in this work concur with those in the literature. For example, Astals et al. (2015), studying the AcoD of pig manure and algae, showed that codigestion performance (methane yield and kinetics) could be assessed by combining the results from mono-substrate digestion experiments and confirmed that degradation kinetics were not influenced by co-digestion. Furthermore, the decrease in MY at higher OLRs for $\mathrm{C}+\mathrm{B}$ and $\mathrm{C}+\mathrm{CM}$ is comparable with several studies investigating the effect of increasing OLR on reactor performance. Similarly, the decrease in MY with a rise in OLR was also found in the study of Xie et al., (2012) investigating the co-digestion of separated pig manure with dried grass silage. The authors reported a drop in MY from 262 to $164\left(\mathrm{LCH}_{4} \mathrm{gVS}^{-1}\right)$ at 1 and $3 \mathrm{kgVS} \mathrm{m}^{-3} \mathrm{~d}^{-1}$, respectively. Alvarez and Lidén (2008) investigated the co-digestion of manure, fruit and vegetable waste (FVW) and solid slaughterhouse waste in 2L semi-continuous reactors at mesophilic conditions with increasing OLRs. The authors reported MYs in the range $0.237-0.350 \mathrm{~m}^{3} \mathrm{~kg}^{-1} \mathrm{VS}_{\text {added }}$ at OLR up to $1.3 \mathrm{kgVS} \mathrm{m}^{3} \mathrm{~d}^{-1}$ but a fall in MY was shown as the OLR increased. MY measured at $3.8 \mathrm{kgVS} \mathrm{m}^{3} \mathrm{~d}^{-1}$ was $0.120 \mathrm{~m}^{3} \mathrm{~kg}^{-1} \mathrm{VS}_{\text {added }}$ which they explained by an 
organic overload or insufficient digester buffering capacity which led to reduced methanogenic activity. Moreover, Comino et al. (2010) studied the co-digestion of cow manure and crop silage in a pilot biogas plant in continuous operation. The reported MYs were 237, 249 and $61 \mathrm{~L} \mathrm{CH}_{4} \mathrm{~kg} \mathrm{VS}^{-1}$ at $4.45,5.15$ and $7.78 \mathrm{~g} \mathrm{VS} \mathrm{L}^{-1} \mathrm{~d}^{-1}$, the process broke down at the highest OLR.

\subsection{Simple modeling approaches for the prediction of methane production in co-} digestion

The objective of modeling was to simulate the weekly methane production from codigestion reactors fed with two substrates and operated at different OLRs in order to determine whether it is possible: firstly, to use data acquired in batch mode to simulate semi-continuous operation; and, secondly, to predict the evolution of methane yield at increasing applied loads.

It was shown in the previous paragraph, that, in semi continuous operation, methane yields (MYs) were higher than the calculated BMPs for all the mixtures at all OLRs linked to the methane production due to endogenous activity. Hence, a two-step modeling approach has been adopted based on the substrate database established by Kouas et al., (2017) and integrating the endogenous production. Thereupon, the prediction of the total methane production in semi-continuous reactors was based on the cumulation of the calculated methane production from the added co-substrates and from the endogenous activity. In a first step, weekly methane production from each cosubstrate was simulated independently according to Eq. (1) to Eq. (5), using the respective VS quantities added (with five feedings per week) along with the individual data acquired in batch mode, i.e. the BMP, the three sub-fractions and the three 
degradation kinetics $\left(3 S_{i}(0), 3 k_{i}\right.$, see table 1$)$. Then, methane productions from the two co-substrates were cumulated, assuming additivity, to calculate the total methane production from the feeding. In a second step, endogenous activity was calculated (see below) and added to the methane production from the substrates in order to assess the total methane production from the reactor.

In the present study, four models were evaluated with two different hypotheses for calculating both methane production from the substrate (using kinetics identified at $95 \%$ or $80 \%$ from the final reaction time in batch) and from endogenous activity (constant or variable EP) as described in figure 4. The four models were compared using the experimental results of the co-digestion of four different mixtures of two substrates.

In the first model, the methane production from the substrates was calculated using the fractionation and the degradation kinetics of each co-substrate determined from the curve of methane produced over time in batch with time stopped at $95 \%$ of final reaction time, that is to say the time when the sludge was back to its endogenous activity i.e. the time at which it could be assumed that the reaction was over and the organic matter added at the beginning of the batch eliminated (Table 1). In this model, EP was calculated assuming a constant rate of $8.7 \pm 1.5 \mathrm{~mL} \mathrm{CH}_{4} \mathrm{~h}^{-1}$ for each reactor, which was measured at the lowest OLR used. By way of example, a comparison of the experimental and modeled results for model\#1, for $\mathrm{C}+\mathrm{CM}$ at four different OLRs, is presented in Fig. 5. The results show that the first model generally underestimated the volume of methane produced compared to experimental values, and therefore the MYs, at all OLRs except $0.5 \mathrm{gVS} \mathrm{L}^{-1} \mathrm{~d}^{-1}$. Furthermore, an excessively important decrease of MY was predicted with the increase in the OLRs for all the mixtures as shown in Fig. 6. The simulation of the evolution of each substrate's sub-fractions over time and the 
calculation of the remaining organic matter quantity at the end of the week (data shown in Supplementary material section) suggested that the quantity of organic matter which was eliminated was underrated, linked to an underestimation of the slowlybiodegradable sub-fraction degradation rate in batch conditions when compared to semicontinuous mode, as already reported (Batstone et al., 2009; Poggio et al., 2016).

For the second model, the fractionation and the kinetics were identified from the methane production curve in batch mode which was stopped at $80 \%$ of the final reaction time in order to give less importance to the organic matter with very slow degradation rates. Consequently, the value of $k_{3}$ increased and was doubled for beef meat, bread and cow manure and reached the value of $k_{2}$ identified from the methane production curve stopped at $95 \%$ of the final reaction time for carrot, tomato and cabbage. Insignificant variations were found for $k_{1}, k_{2}$ and $S_{i}$ and very close values were recorded at $95 \%$ and $80 \%$ of batch reaction time for these parameters (See more details in Supplementary material). Methane production from the co-substrates added was recalculated taking into account the new $k_{3}$ values. Fig. 5 shows that the prediction of total methane production by the second model was significantly improved compared to the first model and the percentage of difference between the modeled and experimental MYs were significantly lower; see Table 2 and Fig. 5. Furthermore, model\#2 still predicted a decrease of MY with the increase of OLR but on a gentler slope than model\#1. As a consequence, MY prediction was excellent for substrates for which MY decreased with increasing loads, $\mathrm{C}+\mathrm{B}$ and $\mathrm{C}+\mathrm{CM}$, and acceptable for $\mathrm{C}+\mathrm{Cab}$ and $\mathrm{T}+\mathrm{BM}$ whose $\mathrm{MY}$ was almost constant throughout the range of OLRs applied (Fig. 6). Overall, the percentages of difference were occasionally higher than $10 \%$ for 6 OLRs out of 29 tested. 
In a second approach (models \#3 and \#4, see Fig. 4) and still in order to increase the total volume of methane produced compared to model\#1, it was assumed that the endogenous methane production (or final methane production rate (FMPR)) increased with the OLR, as presented in Fig. 3, and the following linear correlation between endogenous methane production (EP) and the OLR was used to calculate the endogenous methane production rate at each OLR (Eq. (7)): $E P=14.43 * O L R$

As previously, the volume of methane produced in semi-continuous operation was calculated by adding the volume of methane produced by endogenous activity and the modeled net methane production at each OLR using batch kinetic data assessed at either $95 \%($ model\#3) or at $80 \%$ (model\#4) of final time.

Using model\#3, MYs were overestimated for $\mathrm{C}+\mathrm{B}$ and $\mathrm{C}+\mathrm{CM}$ but underestimated for $\mathrm{C}+\mathrm{Cab}$ and $\mathrm{T}+\mathrm{BM}$. It predicted a lower decrease of the MY than the two first models when the OLR was increased. Overall, this model provided quite a good prediction of methane production, with DPs lower than $10 \%$ for all mixtures at all OLRs except for $\mathrm{C}+\mathrm{CM}$ at the higher OLRs. Concerning model\#4, it predicted almost constant MYs for all the mixtures at all OLRs.

In order to choose the best model, a comparison between models with different hypotheses was carried out. Firstly, The comparison between models \#1 (with constant ER) and \#3 (with increasing ER), both with kinetics assessed at $95 \%$ of the final time in batch mode, showed a clear improvement of the predictive capacities for all mixtures at all OLRs (Fig. 6), except for C+CM at OLRs of $2.5 \mathrm{gVS} \mathrm{L}^{-1} \mathrm{~d}^{-1}$ and above, for which identical results were obtained with both models. Furthermore, model\#3 enhanced the fit between experimental and modeled methane production curves for all digesters at all 
applied OLRs, with a rAE lower than $20 \%$. The comparison between models \#2 (with constant ER) and \#4 (with increasing ER), both with kinetics assessed at $80 \%$ of the final time in batch mode, highlighted two trends. Indeed, model\#2 gave a better fit for both MYs and kinetics with DP below10\% and rAE lower than $20 \%$ for mixtures whose MY decreased with the increase of the OLR $(\mathrm{C}+\mathrm{B}$ and $\mathrm{C}+\mathrm{CM})$, except for OLRs lower than $1.75 \mathrm{gVS} \mathrm{L}^{-1} \mathrm{~d}^{-1}$. However, for $\mathrm{C}+\mathrm{Cab}$ and $\mathrm{T}+\mathrm{BM}$ with fairly constant MYs, model\#4 gave a better prediction of methane production at almost all OLRs.

Finally, a comparison was made between model\#2, with constant endogenous production but increased kinetics for the slowest biodegradable fraction $\left(k_{3}\right)$ (kinetics assessed at $80 \%$ of the batch reaction time), and model\#3, with variable endogenous production and kinetics assessed at $95 \%$ of the reaction time. Overall, both models behaved in quite a similar way and gave close predictions of the methane production with increasing OLRs. Indeed, for all the mixtures and for the 29 applied OLRs, DPs were higher than $10 \%$ in 6 cases for model\#2 and 5 cases for model\#3. Compared to model\#1, models \#2 and \#3 gave better predictions and, despite the different assumptions considered, both models predicted closely the experimental data. In fact, the underestimation of methane production in model\#1 was compensated by increasing the degradation rate of the slowest degradable sub-fraction $\left(k_{3}\right)$ in model \#2 or by increasing endogenous production with increasing OLRs in model\#3. At steady state, however, VSS concentration for all digesters at increasing OLR was constant suggesting that the microbial community was fairly constant in the used experimental conditions. It also suggests that model\#2 appeared to give the closest description of actual processes with constant EP compared to model\#3 with variable EP. Subsequently, model\#2 
seemed to be more appropriate for predicting methane production in a semi-continuous reactor, with an acceptable difference with the experimental data.

The presented results are comparable with those reported by García-Gen et al. (2015) using a modified ADM1 model, with a DP between the modeled and the experimental MYs of $8 \%, 17.90 \%$ and $14.57 \%$ for a digester fed with a mix of five fruit and vegetable waste in a semi-continuous reactor at OLRs of $2,3.79$ and $4.73 \mathrm{gVS} \mathrm{L}^{-1} \mathrm{~d}^{-1}$, respectively. Even with $17.90 \%$, the simulation was considered as acceptable and they reported a very satisfying validation of the model used. Furthermore, Fitamo et al. (2016) reported a difference percentage between the experimental and modeled methane productivity of $11 \%$ using the bioModel developed by Angelidaki et al. (1999) and assumed as insignificant difference for CSTRs operated in co-digestion system at different HRT and fed with a mix of food with garden wastes with primary sludge.

The results described in this section validate the use of data from kinetic characterization of substrates in batches for simulating semi-continuous digesters using a simple model, with acceptable differences. However, substrate degradation kinetics should be assessed from the methane production curve stopped at $80 \%$ of the final batch reaction time to better identify the rate of the slowly-biodegradable fraction $\left(k_{3}\right)$.

Furthermore; EP should be assessed at a low OLR $\left(0.5 \mathrm{gVS} \mathrm{L}^{-1} \mathrm{~d}^{-1}\right)$ and considered as constant at steady state with constant VSS concentration.

\section{Conclusion}

Four co-digestion reactors fed with different mixtures of two substrates were operated in semi-continuous mode at increasing OLRs. Experimental MYs were always higher than the BMP values of mixtures calculated from the BMP of each substrate, showing the important role of EP. Four models were proposed to predict weekly 
methane production with different hypothesis to assess co-substrate parameters and EP. The best agreement between experimental and modeled results was obtained with constant EP and kinetics assessed at $80 \%$ of batch time. This results suggests that it is possible to predict methane production in semi-continuous reactors using data acquired in batch.

\section{Acknowledgments}

The authors gratefully acknowledge the financial support provided by the Franco-

Tunisian PHC-Utique programme managed by the CMCU (Comité Mixte de

Coopération Universitaire) and by the Ministry of Higher Education and Scientific

Research, Tunisia, University of Gabès, Faculty of Sciences. The authors would also

like to thank the Treasure research network (www.inra.fr/treasure).

\section{Appendix A. Supplementary data}

Supplementary data associated with this article can be found, in the online version of the paper.

\section{Reference}

1. Agyeman, F.O., Tao, W., 2014. Anaerobic co-digestion of food waste and dairy manure: Effects of food waste particle size and organic loading rate. J. Environ. Manage. 133, 268-274.

2. Alvarez, R., Lidén, G., 2008. Semi-continuous co-digestion of solid slaughterhouse waste, manure, and fruit and vegetable waste. Renew. Energy. 33, 726-734.

3. Angelidaki, I., Ellegaard, L., Ahring, B., 1999. A comprehensive model of anaerobic bioconversion of complex substrates to biogas. Biotechnol. Bioeng. 63, 363-372.

4. APHA, AWWA, WPDF, Standard Methods for the Examination of Water and Wastewater, 21st ed., American Public Health Association, Washington DC, 2005.

5. Astals, S., Esteban-Gutiérrez, M., Fernández-Arévalo, T., Aymerich, E., García-

Heras, J.L., Mata-Alvarez, J., 2013. Anaerobic digestion of seven different sewage 
sludges: A biodegradability and modelling study. Water Res. 47, 6033-6043.

6. Astals, S., Musenze, R.S., Bai, X., Tannock, S., Tait, S., Pratt, S., Jensen, P.D., 2015.

Anaerobic co-digestion of pig manure and algae: Impact of intracellular algal products recovery on co-digestion performance. Bioresour. Technol. 181, 97-104.

7. Batstone, D.J., Tait, S., Starrenburg, D., 2009. Estimation of hydrolysis parameters in full-scale anerobic digesters. Biotechnol. Bioeng. 102, 1513-20.

8. Boubaker, F., Ridha, B.C., 2008. Modelling of the mesophilic anaerobic co-digestion of olive mill wastewater with olive mill solid waste using anaerobic digestion model No. 1 (ADM1). Bioresour. Technol. 99, 6565-77.

9. Cazier, E.A., Trably, E., Steyer, J.P., Escudie, R., 2015. Biomass hydrolysis inhibition at high hydrogen partial pressure in solid-state anaerobic digestion. Bioresour. Technol. 190, 106-113.

10. Charnier, C., Latrille, E., Jimenez, J., Torrijos, M., Sousbie, P., Miroux, J., Steyer, J.-P., 2017. Fast ADM1 implementation for the optimization of feeding strategy using near infrared spectroscopy. Water Res. 122, 27-35.

11. Comino, E., Rosso, M., Riggio, V., 2010. Investigation of increasing organic loading rate in the co-digestion of energy crops and cow manure mix. Bioresour. Technol. 101, 3013-3019.

12. Donoso-Bravo, A., Mailier, J., Martin, C., 2011. Model selection, identification and validation in anaerobic digestion: a review. Water Res. 45, 5347-5364.

13. Ferrer, P., Cambra-López, M., Cerisuelo, A., Peñaranda, D.S., Moset, V., 2014. The use of agricultural substrates to improve methane yield in anaerobic co-digestion with pig slurry: Effect of substrate type and inclusion level. Waste Manag. 34, 196-203.

14. Fitamo, T., Boldrin, A., Dorini, G., Boe, K., Angelidaki, I., Scheutz, C., 2016. Optimising the anaerobic co-digestion of urban organic waste using dynamic bioconversion mathematical modelling. Water Res. 106, 283-294.

15. Flores-Alsina, X., Solon, K., Kazadi Mbamba, C., Tait, S., Gernaey, K. V., Jeppsson, U., Batstone, D.J., 2016. Modelling phosphorus (P), sulfur (S) and iron $(\mathrm{Fe})$ interactions for dynamic simulations of anaerobic digestion processes.

Water Res. 95, 370-382. 
16. Ganesh, R., Torrijos, M., Sousbie, P., Steyer, J.P., Lugardon, A., Delgenes, J.P., 2013. Anaerobic co-digestion of solid waste: Effect of increasing organic loading rates and characterization of the solubilised organic matter. Bioresour. Technol. 130, 559-569.

17. Gannoun, H., Othman, N. Ben, Bouallagui, H., Moktar, H., 2007. Mesophilic and Thermophilic Anaerobic Co-digestion of Olive Mill Wastewaters and Abattoir

Wastewaters in an Upflow Anaerobic Filter. Ind. Eng. Chem. Res. 46, 6737-6743.

18. Garcia-Gen, S., Lema, J.M., Rodriguez, J., 2013. Generalised modelling approach for anaerobic co-digestion of fermentable substrates. Bioresour. Technol. 147, $525-533$.

19. Garcia-Gen, S., Sousbie, P., Rangaraj, G., Lema, J.M., Rodríguez, J., Steyer, J.-P., Torrijos, M., 2015. Kinetic modelling of anaerobic hydrolysis of solid wastes, including disintegration processes. Waste Manag. 35, 96-104.

20. Gunaseelan, V., 2004. Biochemical methane potential of fruits and vegetable solid waste feedstocks. Biomass and Bioenergy. 26, 389-399.

21. Khalid, A., Arshad, M., Anjum, M., Mahmood, T., Dawson, L., 2011. The anaerobic digestion of solid organic waste. Waste Manag. 31, 1737-1744.

22. Kouas, M., Torrijos, M., Sousbie, P., Steyer, J-P., Sayadi, S., Harmand, J., 2017. Robust assessment of both biochemical methane potential and degradation kinetics of solid residues in successive batches. Waste Manag. 70, 59-70.

23. Labatut, R.A., Angenent, L.T., Scott, N.R., 2011. Biochemical methane potential and biodegradability of complex organic substrates. Bioresour. Technol. 102, $2255-2264$.

24. Mata-alvarez, J., Dosta, J., Macé, S., Astals, S., 2011. Codigestion of solid wastes : A review of its uses and perspectives including modeling. Crit. Rev. Biotechnol. 31, 99-111.

25. Poggio, D., Walker, M., Nimmo, W., Ma, L., Pourkashanian, M., 2016. Modelling the anaerobic digestion of solid organic waste - Substrate characterisation method for ADM1 using a combined biochemical and kinetic parameter estimation approach. Waste Manag. 53, 40-54.

26. Raposo, F., Fernández-Cegri, V., de la Rubia, M.A., Borja, R., Béline, F., Cavinato, 
C., Demirer, G., Fernández, B., Fernández-Polanco, M., Frigon, J.C., Ganesh, R., Kaparaju, P., Koubova, J., Méndez, R., Menin, G., Peene, A., Scherer, P., Torrijos, M., Uellendahl, H., Wierinck, I., de Wilde, V., 2011. Biochemical methane potential (BMP) of solid organic substrates: evaluation of anaerobic biodegradability using data from an international interlaboratory study. J. Chem. Technol. Biotechnol. 86, 1088-1098.

27. Xie, S., Hai, F.I., Zhan, X., Guo, W., Ngo, H.H., Price, W.E., Nghiem, L.D., 2016. Anaerobic co-digestion: A critical review of mathematical modelling for performance optimization. Bioresour. Technol. 222, 498-512.

28. Xie, S., Wu, G., Lawlor, P.G., Frost, J.P., Zhan, X., 2012. Methane production from anaerobic co-digestion of the separated solid fraction of pig manure with dried grass silage. Bioresour. Technol. 104, 289-297.

29. Yazidi, H., Thanikal, J. V, 2016. Non-linear kinetic modelling of anaerobic biodegradation of fruit and vegetable waste together with cooked oil. Int. J. Adv. Res. Biol. Sci. 3, 109-121.

30. Zhang, L., Jahng, D., 2012. Long-term anaerobic digestion of food waste stabilized by trace elements. Waste Manag. 32, 1509-1515.

\section{Figure and table captions}

Fig. 1. Process Performance for the reactor fed with $\mathrm{C}+\mathrm{B}$ : A, evolution of methane production per week over time at increasing OLRs; B, evolution of methane productivity (MP) and methane yield (MY) with OLRs; C, evolution of volatile fatty acids concentration (VFA) and of the final methane production rate (FMPR) with OLRs.

Fig. 2. Process performance: A, evolution of methane productivity (MP); B, evolution of methane yield (MY), in relation to OLR for the four digesters.

Fig. 3. Evolution of the final methane production rates (FMPR) in relation to increasing OLRs for all digesters.

Fig. 4. Modelling approach diagram. 
Fig. 5. Example of the evolution of experimental and modeled (models \#1 and \#2) weekly methane production over time for the reactor fed with $\mathrm{C}+\mathrm{CM}$ at an increasing OLR, (A) 0.5 , (B) 1.75, (C) 2.5 and (D) $2.75 \mathrm{gVS} \mathrm{L}^{-1} \mathrm{~d}^{-1}$.

Fig. 6. Comparison between experimental and modeled methane yields (MY) using the four models proposed for, (A) $\mathrm{C}+\mathrm{B}$, (B) $\mathrm{C}+\mathrm{CM}$, (C) $\mathrm{C}+\mathrm{Cab}$ and (D) $\mathrm{T}+\mathrm{BM}$.

Table 1. Substrate characterization with fractionation of the six substrates into three sub-fractions: Rapidly $\left(\% S_{l}(0), k_{l}\right)$, Moderately $\left(\% S_{2}(0), k_{2}\right)$ and Slowly $\left(\% S_{3}(0), k_{3}\right)$ biodegradable sub-fractions.

Table 2. Comparison between the experimental and the modeled methane yield (MY) using the four proposed models for all digesters at increasing OLRs.

Table 3. Evaluation of kinetic fits between the experimental and the modeled methane production curves by calculation of the relative absolute error (rAE) using the four proposed models with increasing OLRs. 
Table 1. Substrate characterization with fractionation of the six substrates into three sub-fractions: Rapidly $\left(\% S_{l}(0), k_{1}\right)$, Moderately $\left(\% S_{2}(0), k_{2}\right)$ and Slowly $\left(\% S_{3}(0), k_{3}\right)$ biodegradable sub-fractions.

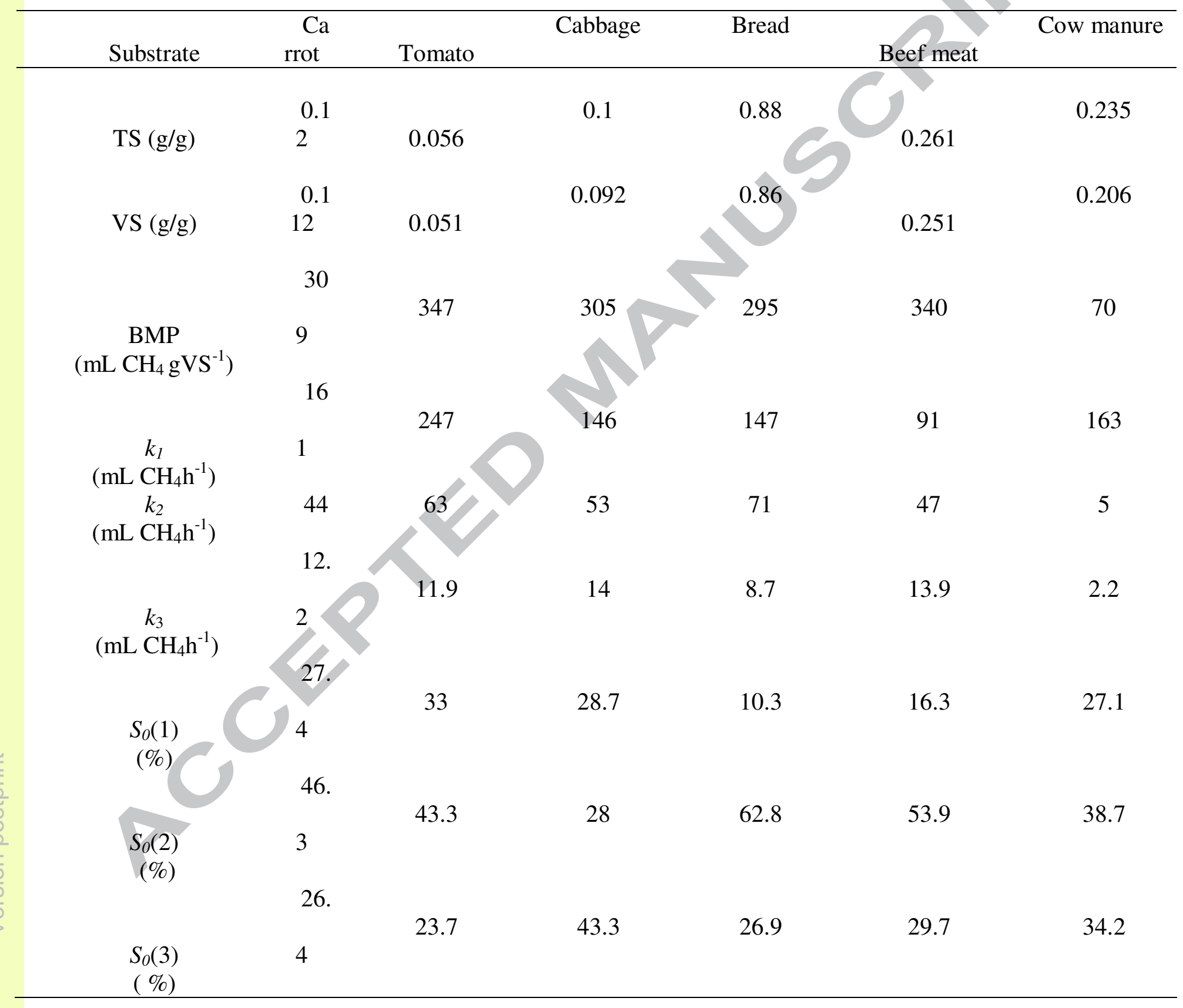


Table 2. Comparison between the experimental and the modeled methane yield (MY) using the four proposed models for all digesters at increasing OLRs.

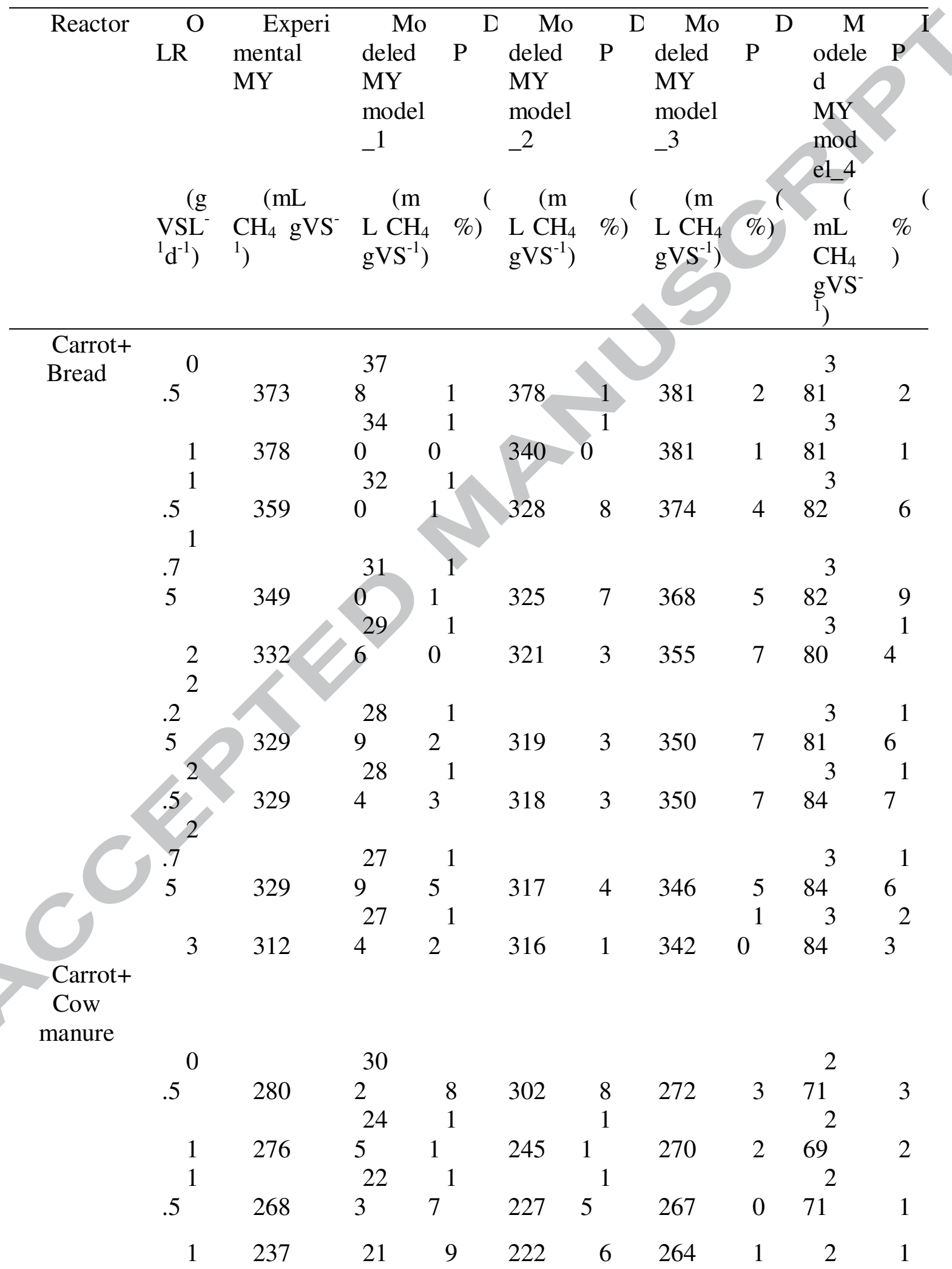




$\begin{array}{lcccccccccc}.7 & & 5 & & & & & 1 & 71 & 5 \\ 5 & & & & & & & & & \\ & & 20 & 1 & & & & & 2 & 1 \\ 2 & 236 & 5 & 3 & 218 & 8 & 258 & 9 & 71 & 5 \\ 2 & & & & & & & & & \\ .2 & & 19 & 1 & & 1 & & & 2 & 1 \\ 5 & 238 & 6 & 8 & 214 & 0 & 253 & 6 & 70 & 3 \\ 2 & & 18 & 1 & & & & 1 & 2 & 2 \\ .5 & 214 & 9 & 1 & 209 & 2 & 248 & 6 & 68 & 5 \\ 2 & & & & & & & & 2 & 2 \\ .7 & & & 18 & 1 & & & & 1 & 2 & 2 \\ 5 & 215 & 3 & 205 & 4 & 244 & 4 & 66 & 4 \\ 3 & 209 & 8 & 5 & 202 & 3 & 241 & 5 & 64 & 6\end{array}$

\section{Carrot $+\mathrm{Ca}$}

bbage

\begin{tabular}{|c|c|c|c|c|c|c|c|c|}
\hline ( & 41 & & & & & & & 3 \\
\hline .5 & $\begin{array}{l}7 \\
37\end{array}$ & 408 & 2 & 408 & 2 & 389 & 7 & $\begin{array}{r}89 \\
3\end{array}$ \\
\hline 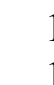 & $\begin{array}{l}2 \\
36\end{array}$ & 357 & & 357 & 4 & 388 & 4 & $\begin{array}{r}88 \\
3\end{array}$ \\
\hline .5 & 6 & & 0 & 341 & 7 & 375 & 2 & 89 \\
\hline & 39 & & 2 & & 1 & & & 3 \\
\hline 5 & 37 & 313 & & 336 & ${ }^{5}$ & 366 & 8 & $\begin{array}{r}89 \\
3\end{array}$ \\
\hline & 2 & 299 & 0 & 333 & 0 & 355 & 5 & 89 \\
\hline & 38 & & 2 & & 1 & & 1 & 3 \\
\hline 2 & $\begin{array}{l}6 \\
36\end{array}$ & 288 & ${ }^{5}$ & 330 & $4_{1}$ & 347 & 0 & $\begin{array}{r}89 \\
3\end{array}$ \\
\hline .5 & 9 & 279 & 4 & 328 & 1 & 341 & 8 & 89 \\
\hline
\end{tabular}

Tomato

+ Beef

meat

\begin{tabular}{ccccccccccc} 
& & 41 & & & & & & 4 & \\
1 & 433 & 1 & 5 & 411 & 5 & 437 & 1 & 37 & 1 \\
1 & & 37 & 1 & & 1 & & & 4 & \\
.5 & 438 & 8 & 4 & 393 & 0 & 422 & 4 & 37 & 0 \\
& & 35 & 1 & & 1 & & & 4 & \\
2 & 428 & 8 & 6 & 384 & 0 & 411 & 4 & 37 & 2 \\
2 & & 32 & 2 & & 1 & & 1 & 4 & \\
.5 & 436 & 8 & 5 & 361 & 7 & 387 & 1 & 20 & 4 \\
\hline
\end{tabular}




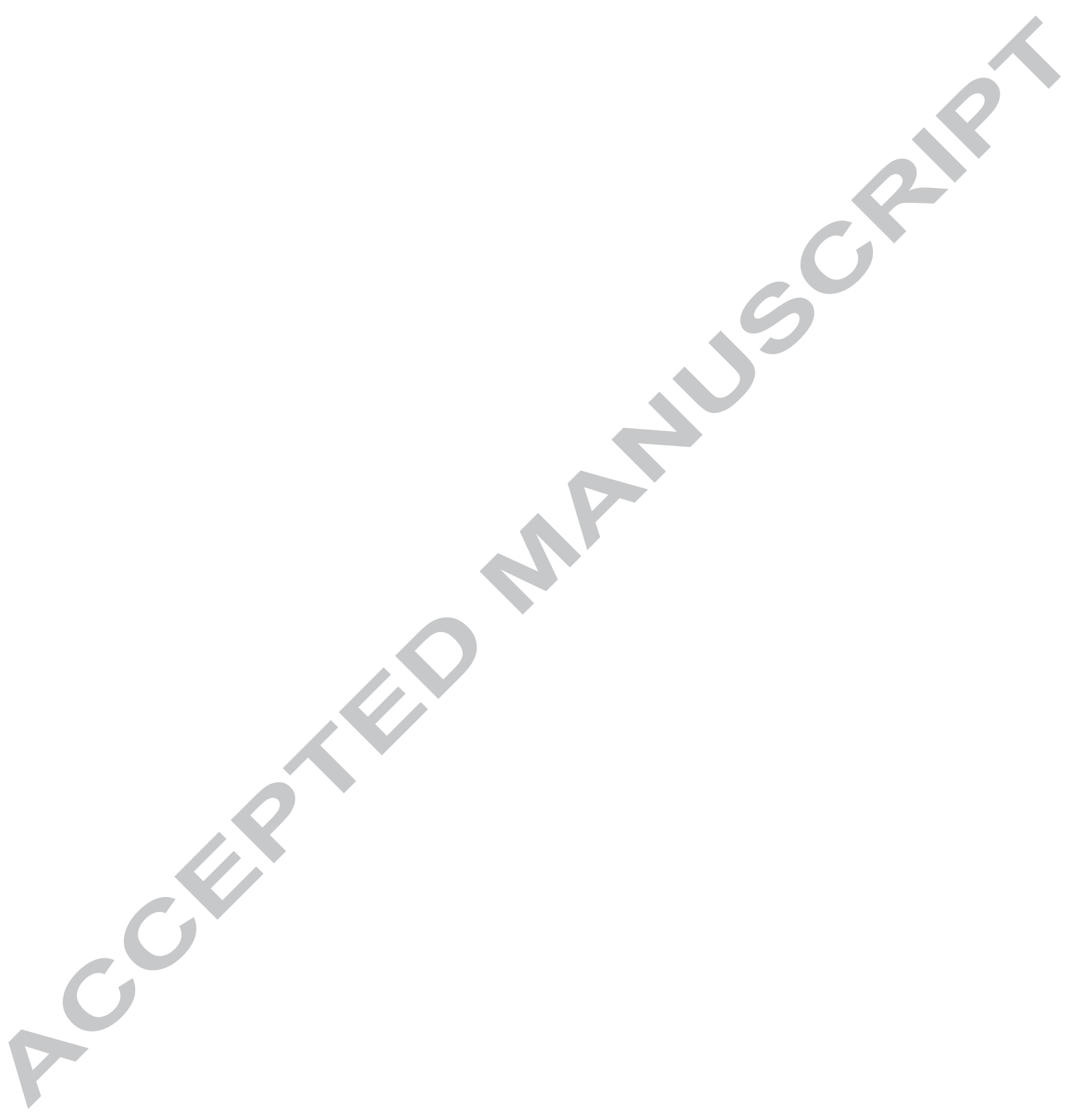


Table 3. Evaluation of kinetic fits between the experimental and the modeled methane production curves by calculation of the relative absolute error (rAE) using the

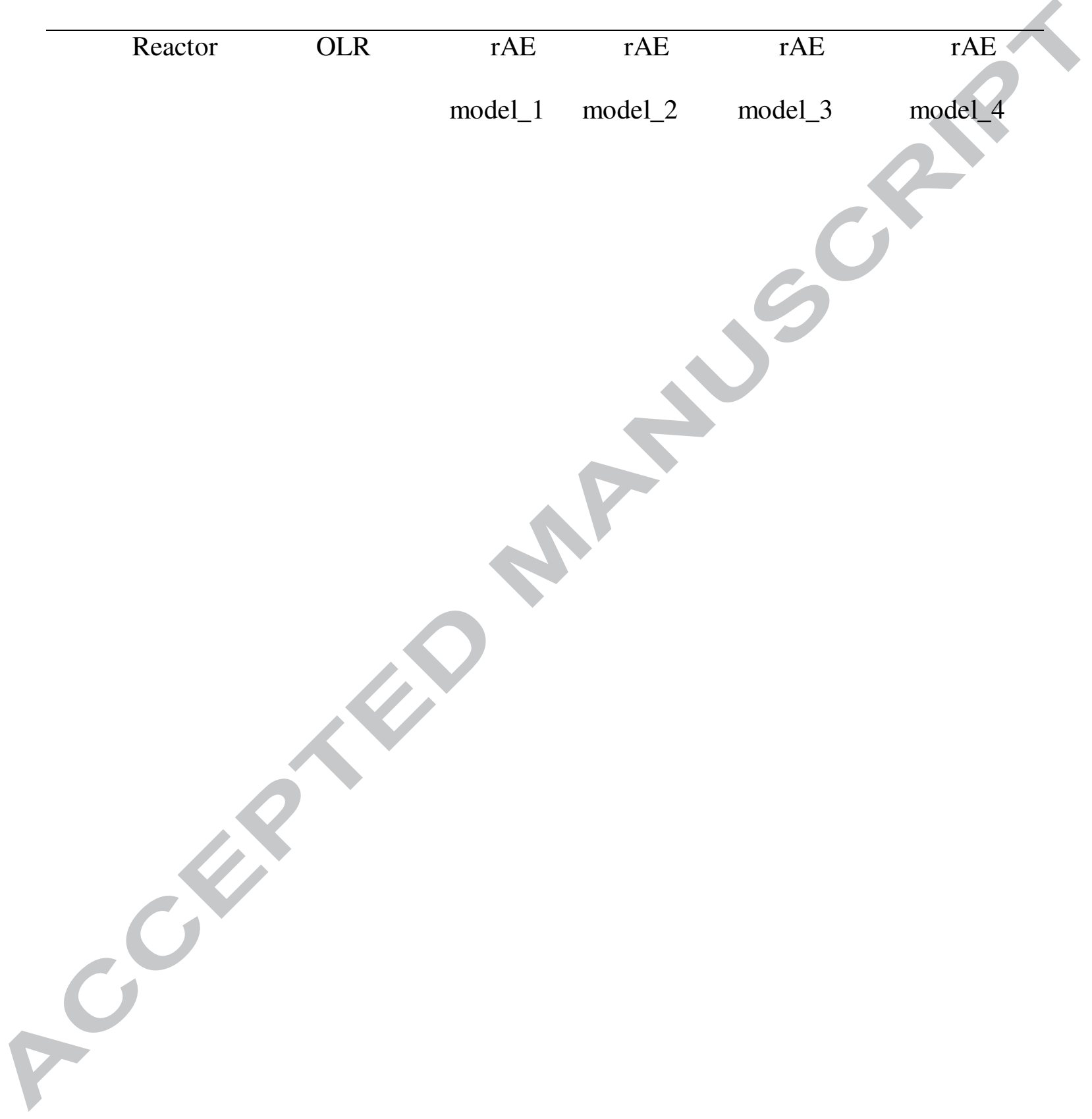

four proposed models with increasing OLRs. 

(g $\mathrm{VSL}^{-} \quad(\%$
$(\%)$
(\%)
(\%)

$\left.{ }^{1} \mathrm{~d}^{-1}\right) \quad$ )

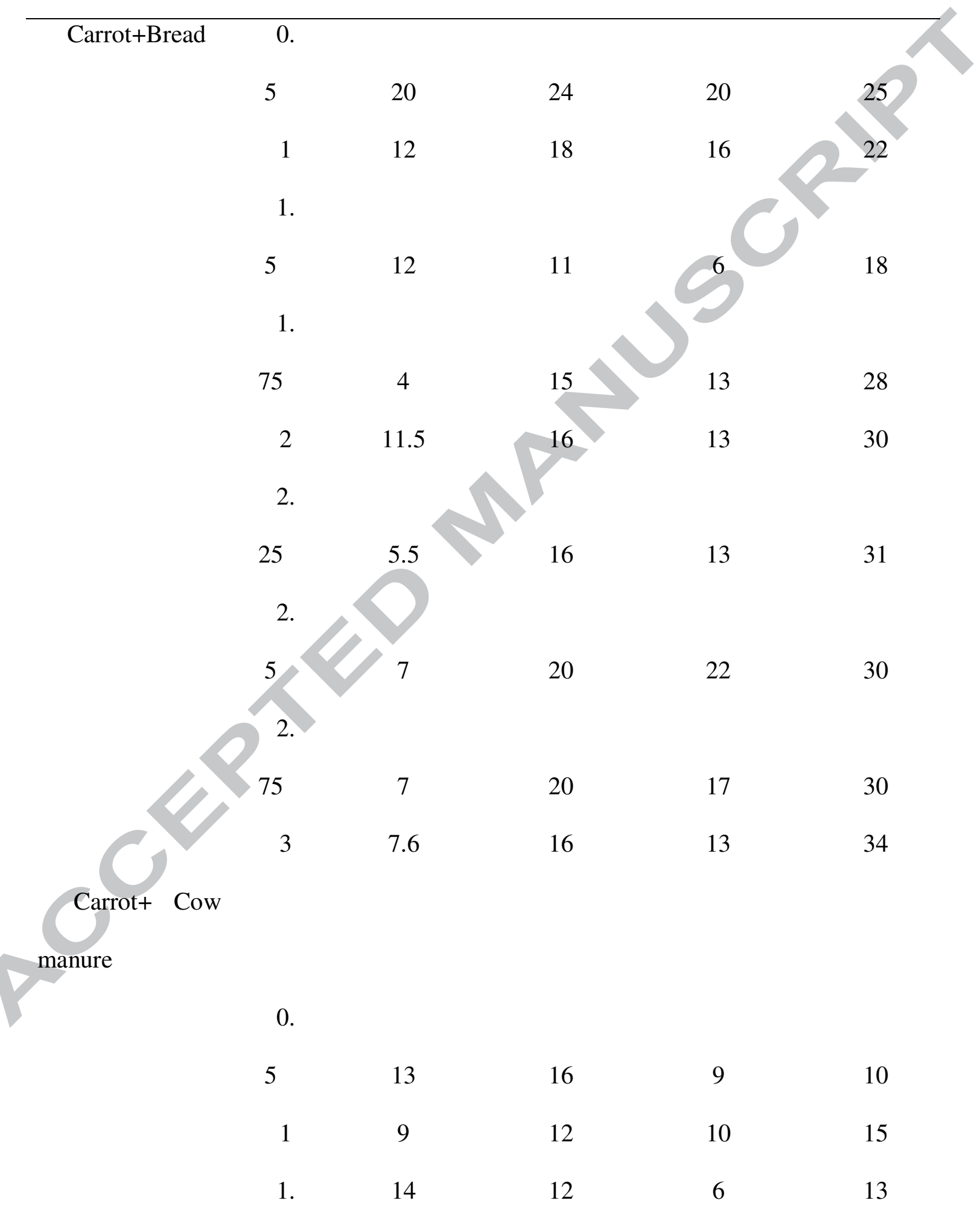




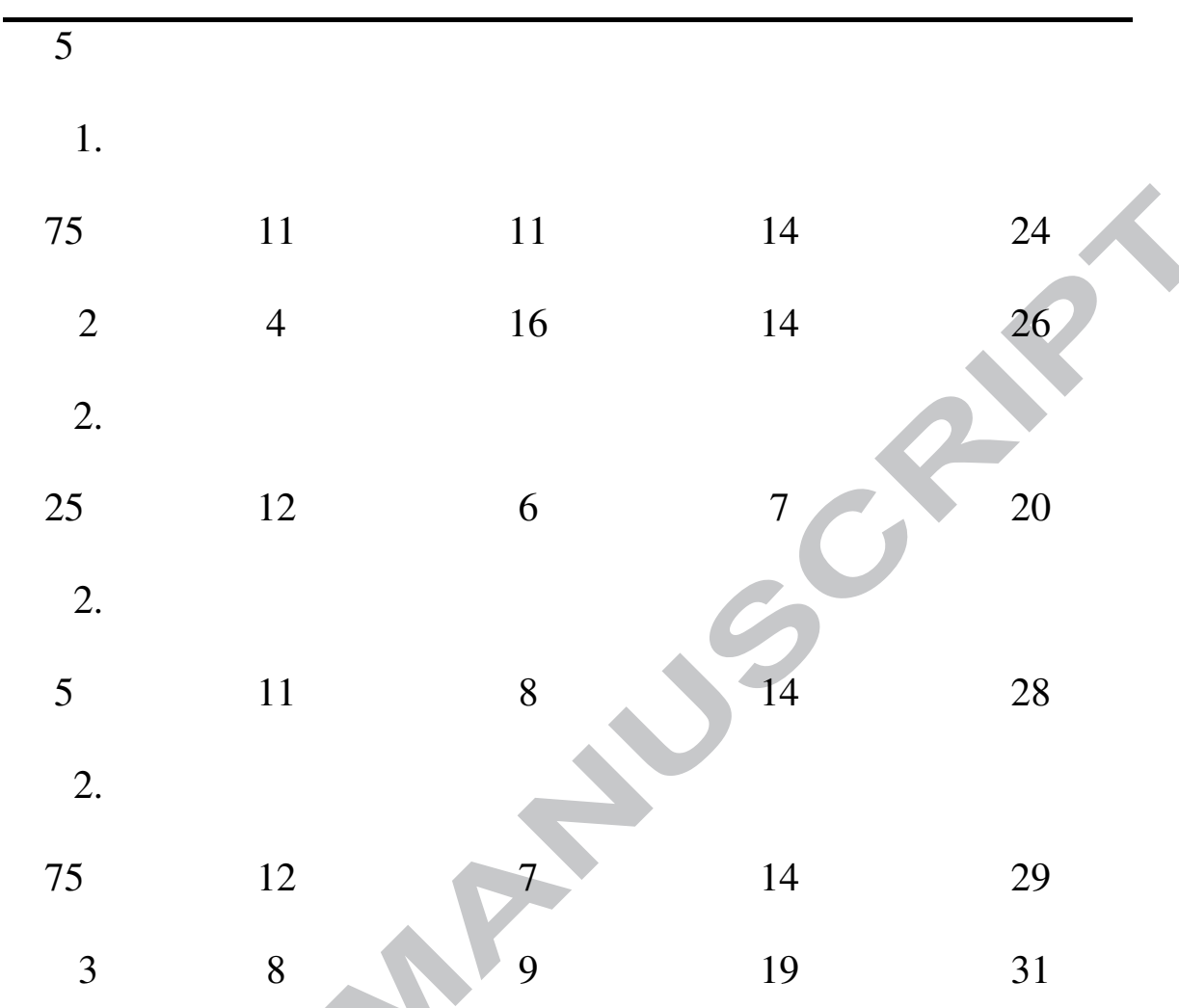

Carrot+Cabba

ge 0.

$\begin{array}{lllll}5 & 10 & 10 & 8 & 10 \\ 1 & 5 & 9 & 5 & 12\end{array}$

1.

5

11

13.

7

20

1.

$\begin{array}{ccccc}75 & 18 & 10 & 9 & 7 \\ 2 & 17 & 9 & 9 & 10 \\ 2 . & 21 & 12 & 13 & 9\end{array}$

33 
25

2.

5

22

8

10

10

\section{Tomato+Beef}

meat

6

10

13

1.

5

13

12

$9 \quad 12$

$2 \quad 17$

2.

19

10

9

5

22

20

17

20 


\section{Highlights}

- Methane yields always greater than calculated BMPs due to endogenous production

- Endogenous production was assessed in semi-continuous reactors

- Validation that data acquired in batch can be used to model semi-continous reactors

- Model allows to forecast the evolution of methane yields at increasing OLRs

- Development of new simple tool to optimize mixtures of solid waste 


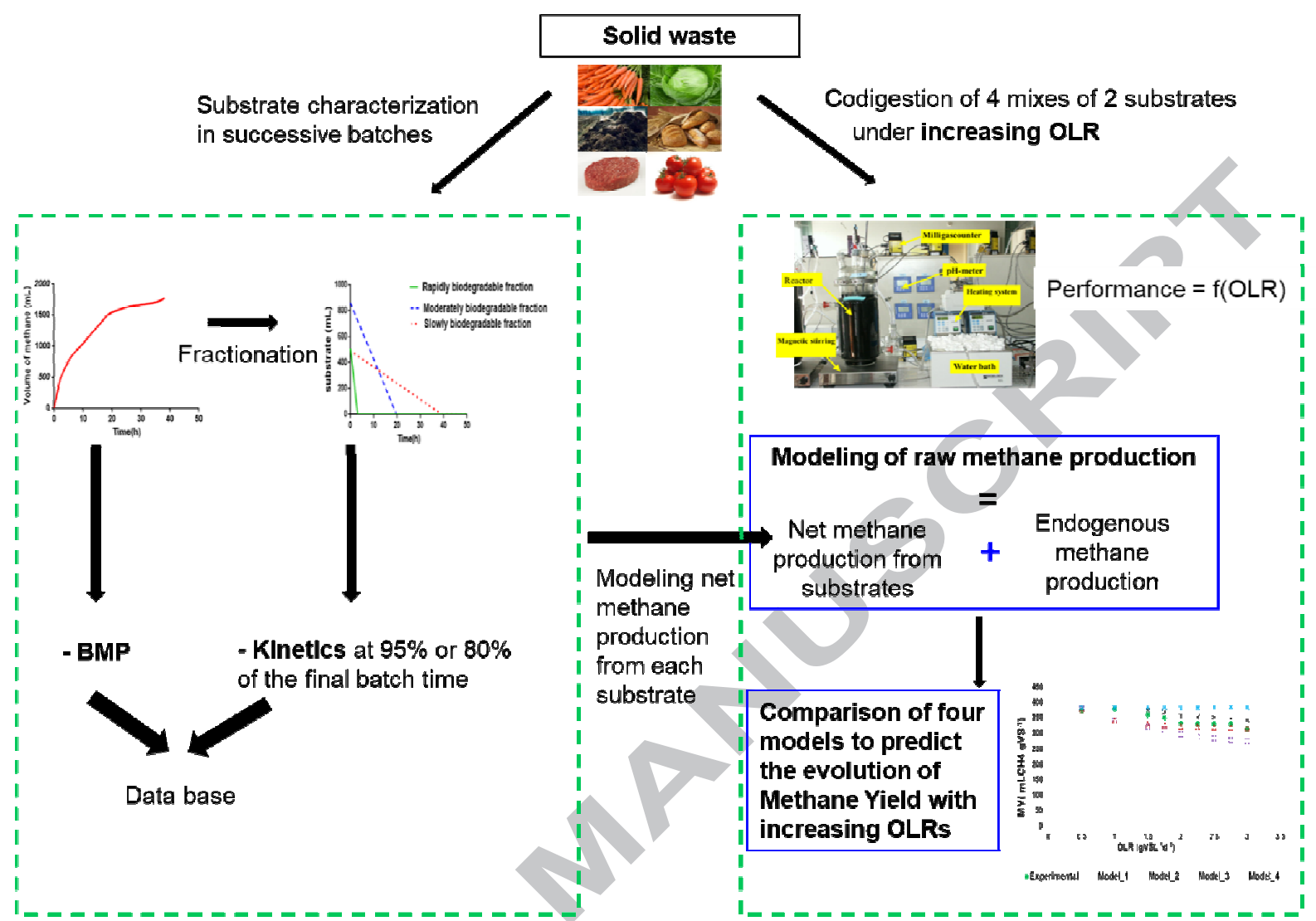

Graphical abstract 

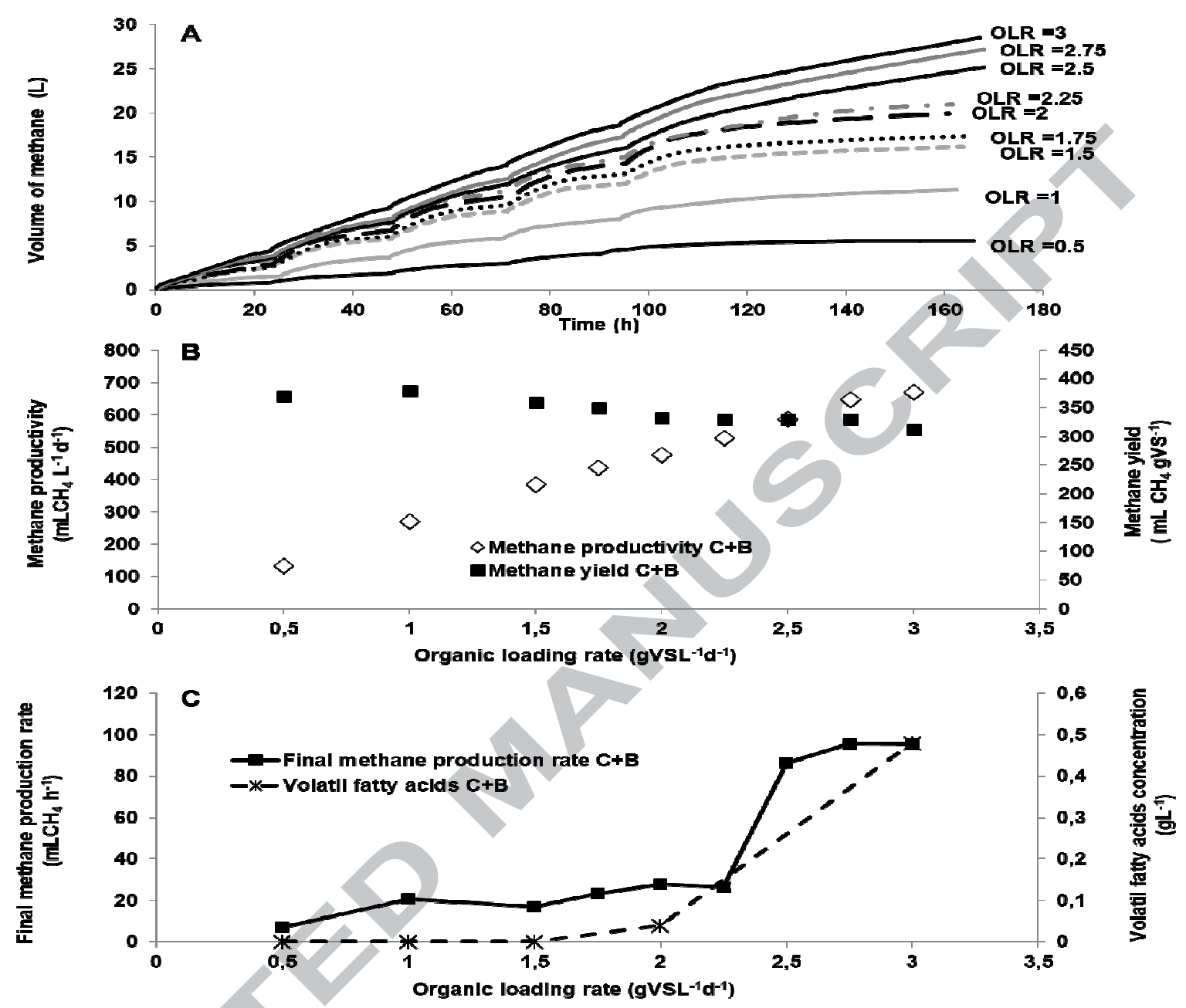

Fig. 1. 


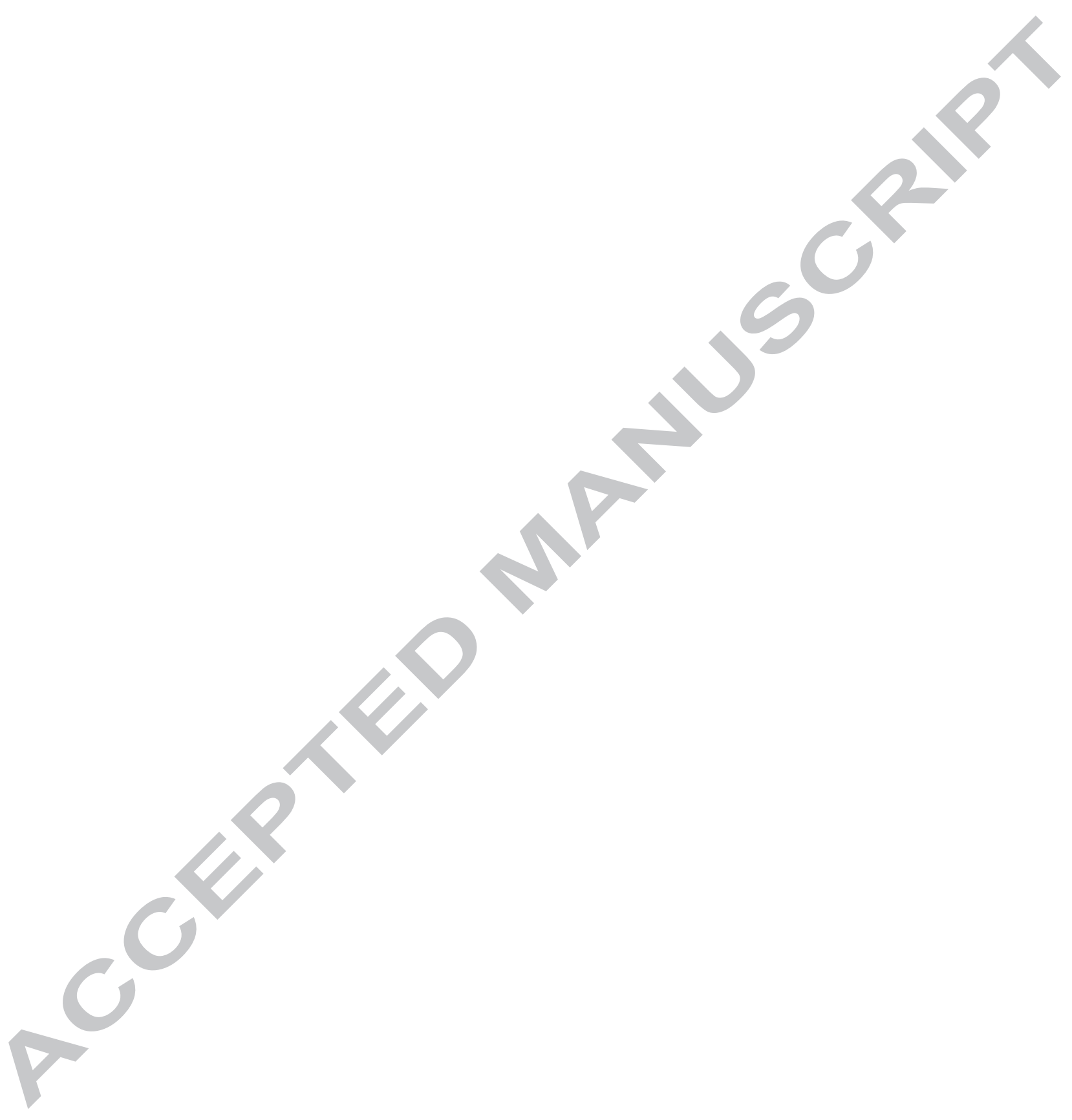


Figure

Click here to download Figure: Figure 2.docx
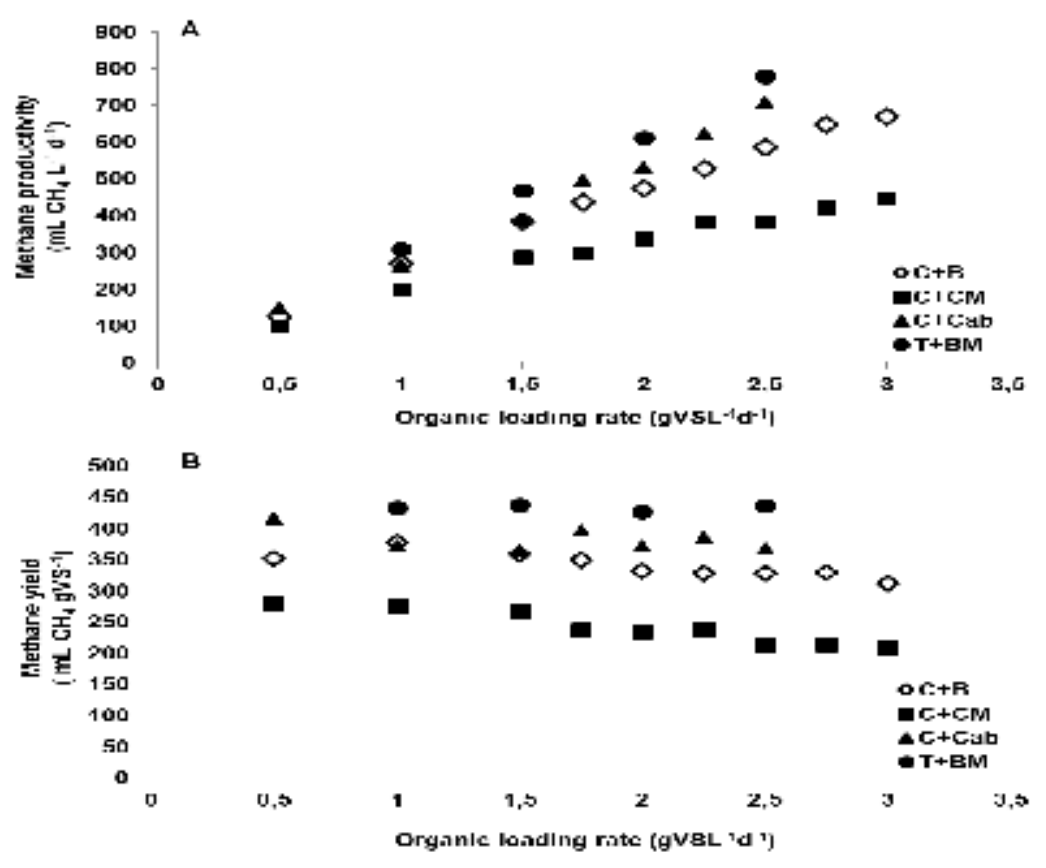

Fig. 2. 


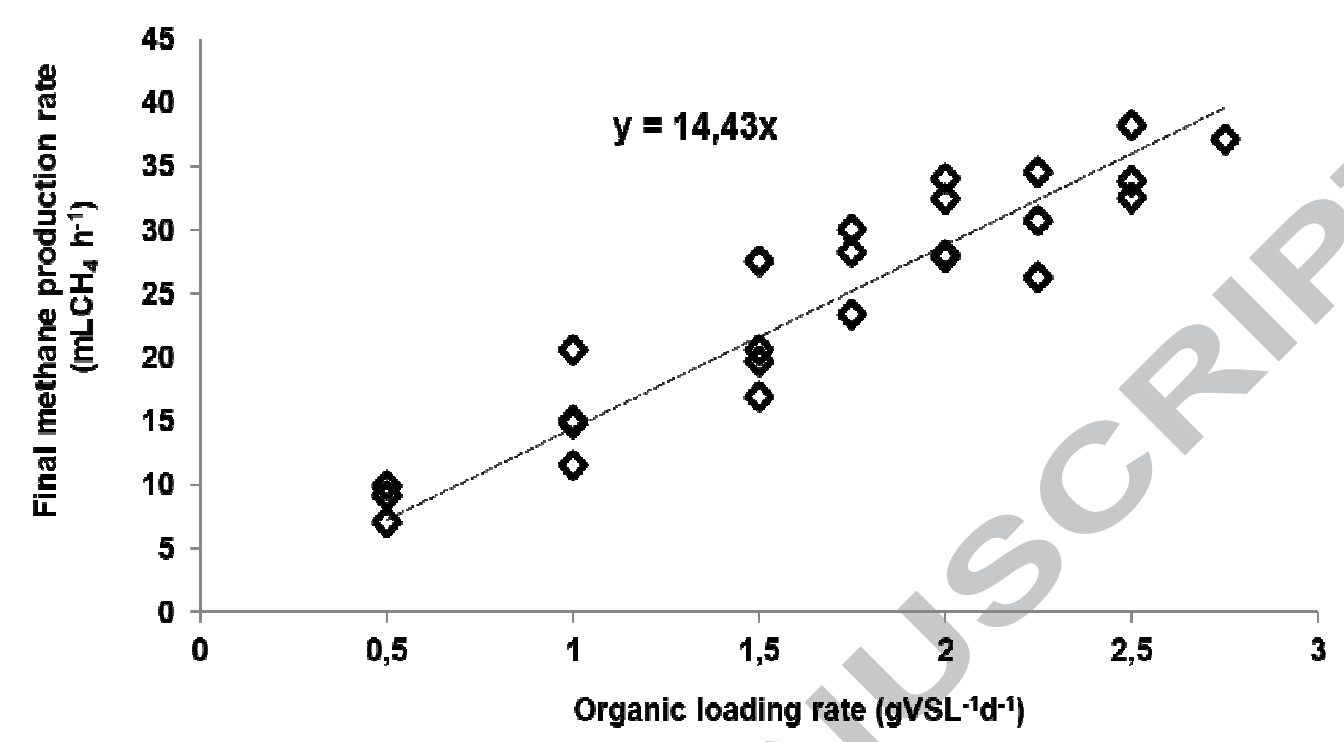

Fig. 3. 
Figure

Click here to download Figure: Figure 4.docx

Prediction of raw methane production in continuous operation under increasing OLR= net methane production from substrates+ endogenous production

\begin{tabular}{|c|c|}
\hline Hyp1:constant endogenous production & Hyp2:variable endagenaus production \\
\hline Modal\#1 & Model\#3 \\
\hline 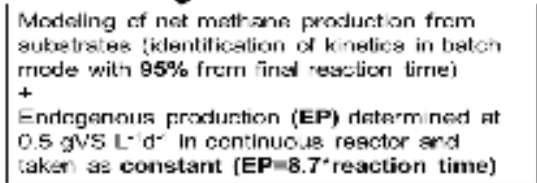 & 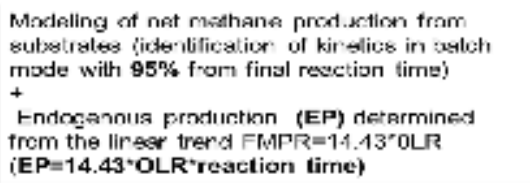 \\
\hline
\end{tabular}

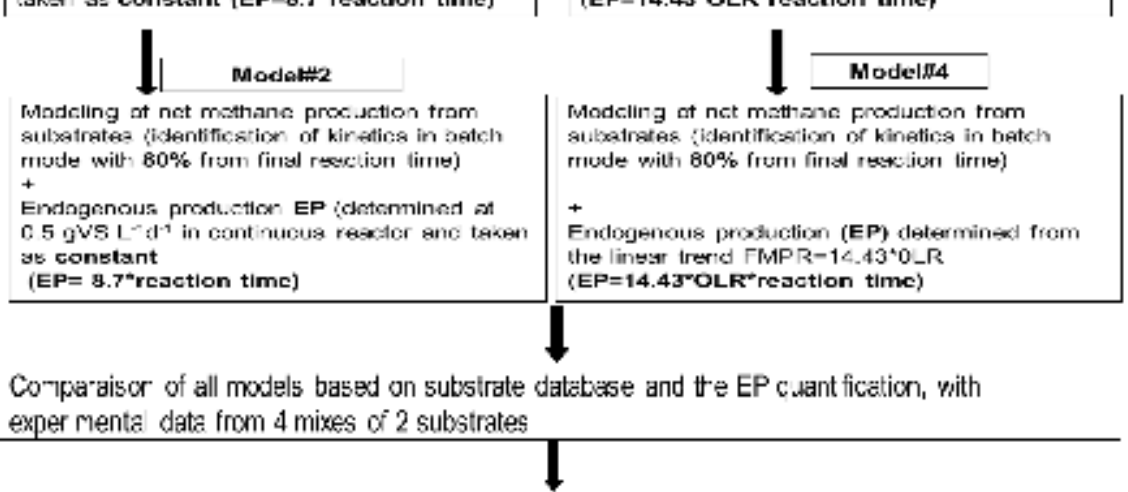

Designing of the optimal model to be appliax for general cases of cc-digestion systems :good correlat on with experinental data $\mathrm{DP}<=10 \%$ and $A \mathrm{AE}<=20 \%$ with the sest identificaticr in tatch mode

Fig. 4. 


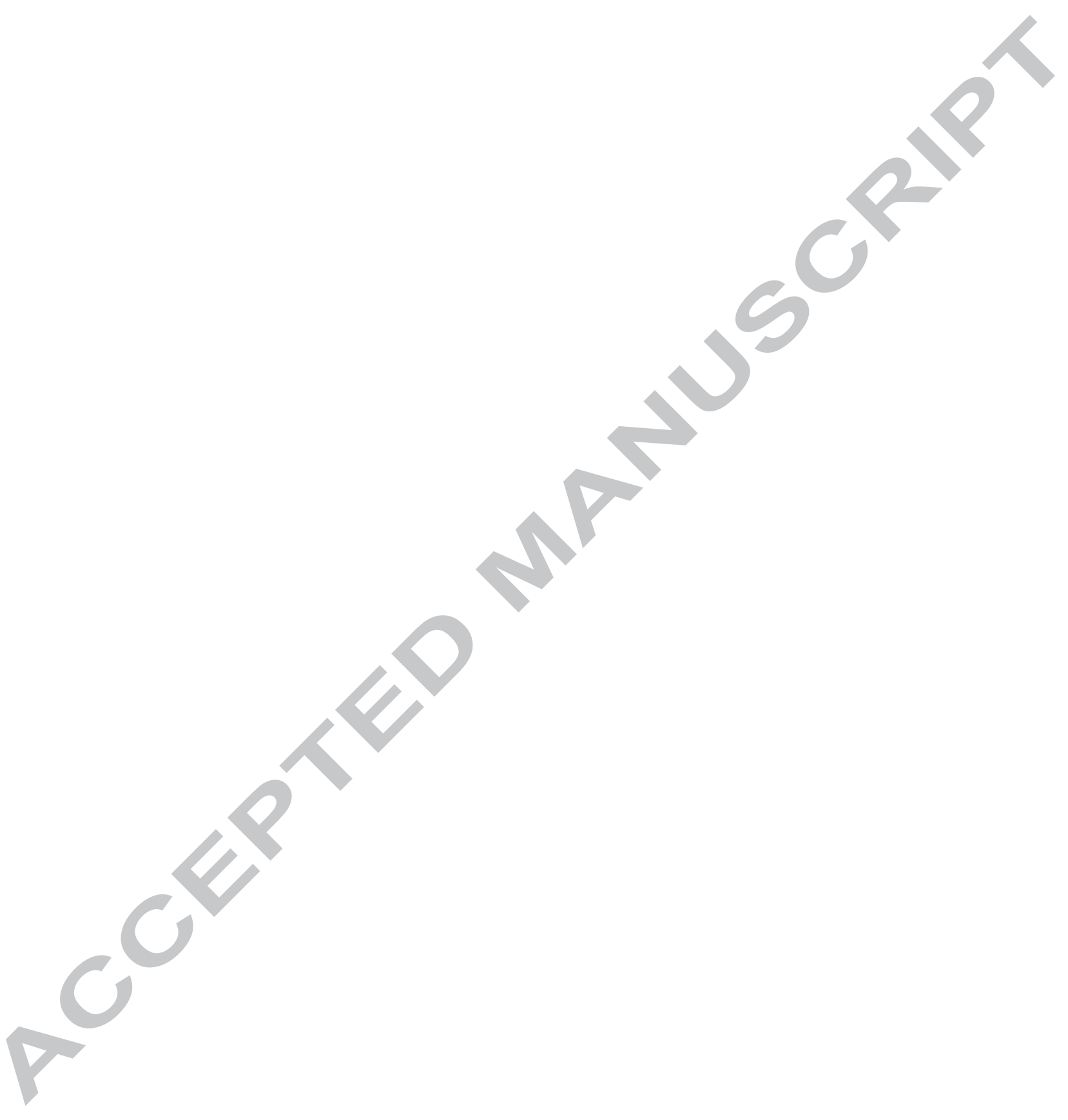



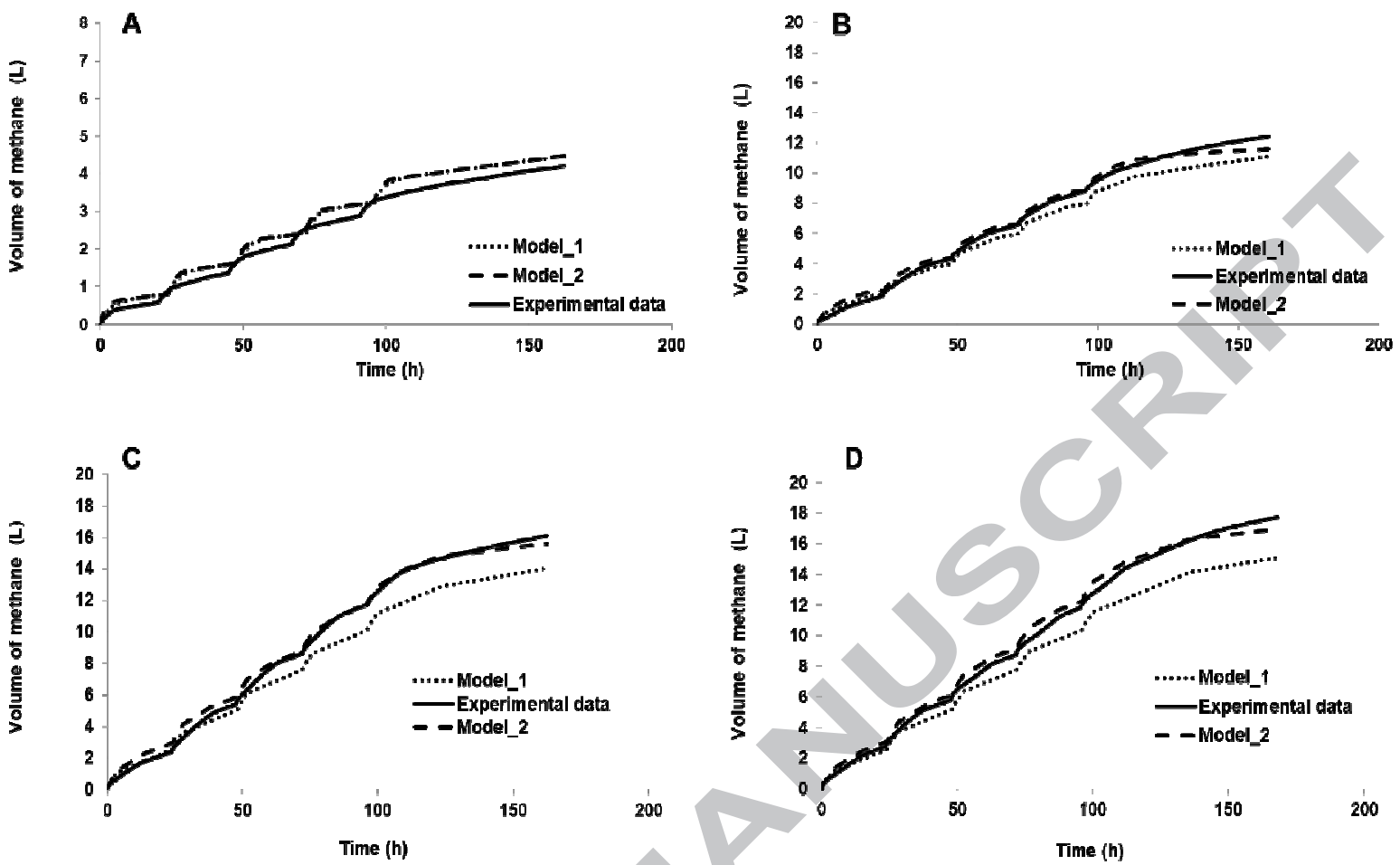

Fig. 5. 


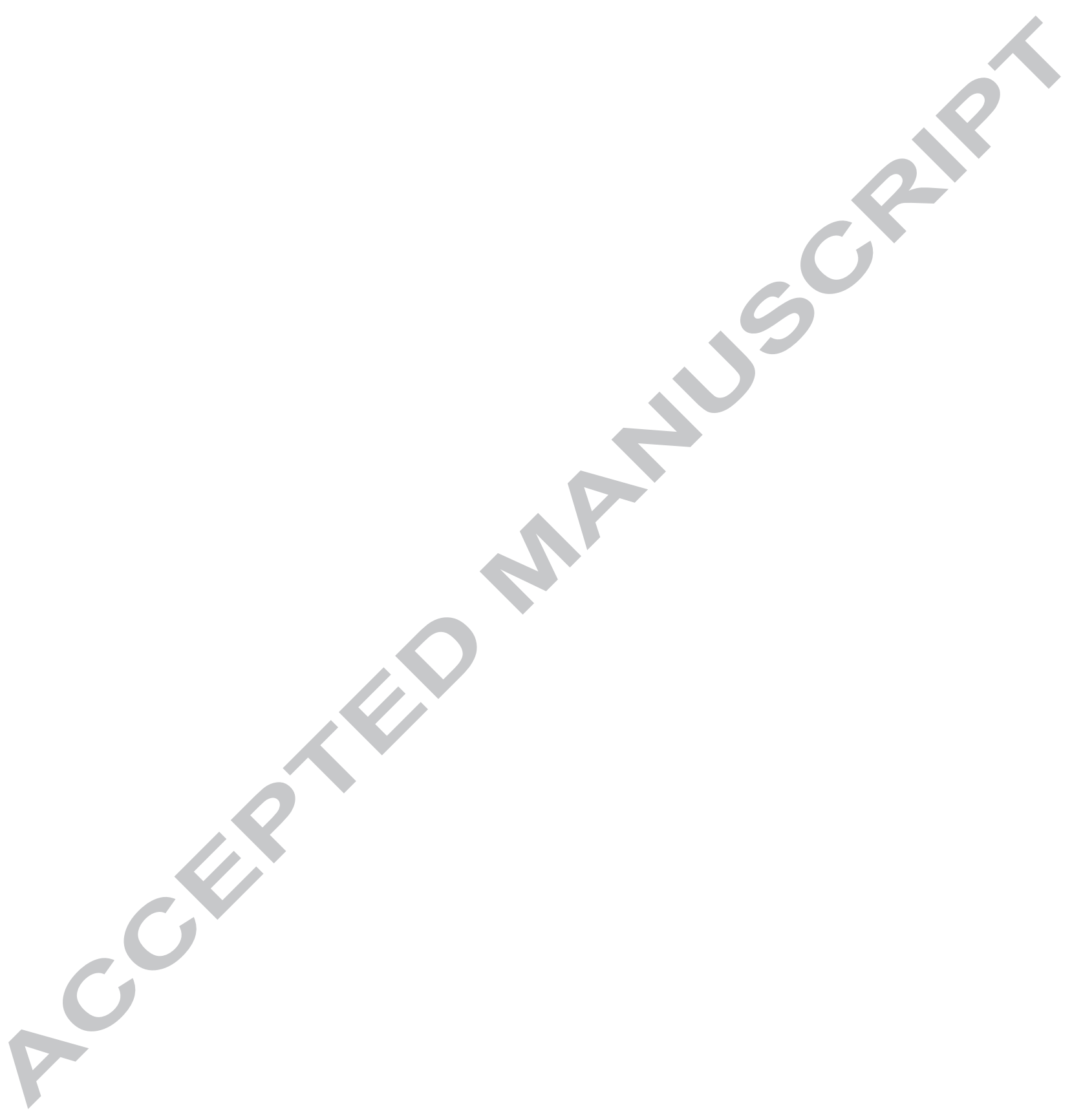


Figure

Click here to download Figure: Figure 6.docx
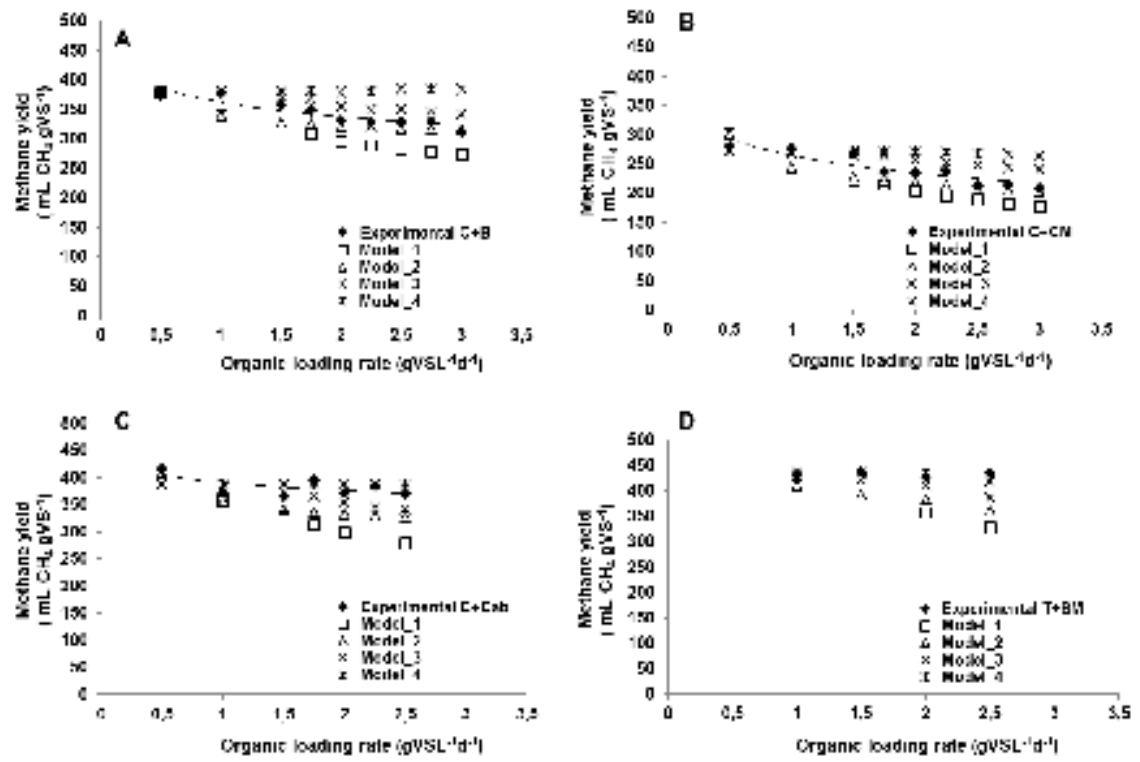

Fig. 6. 


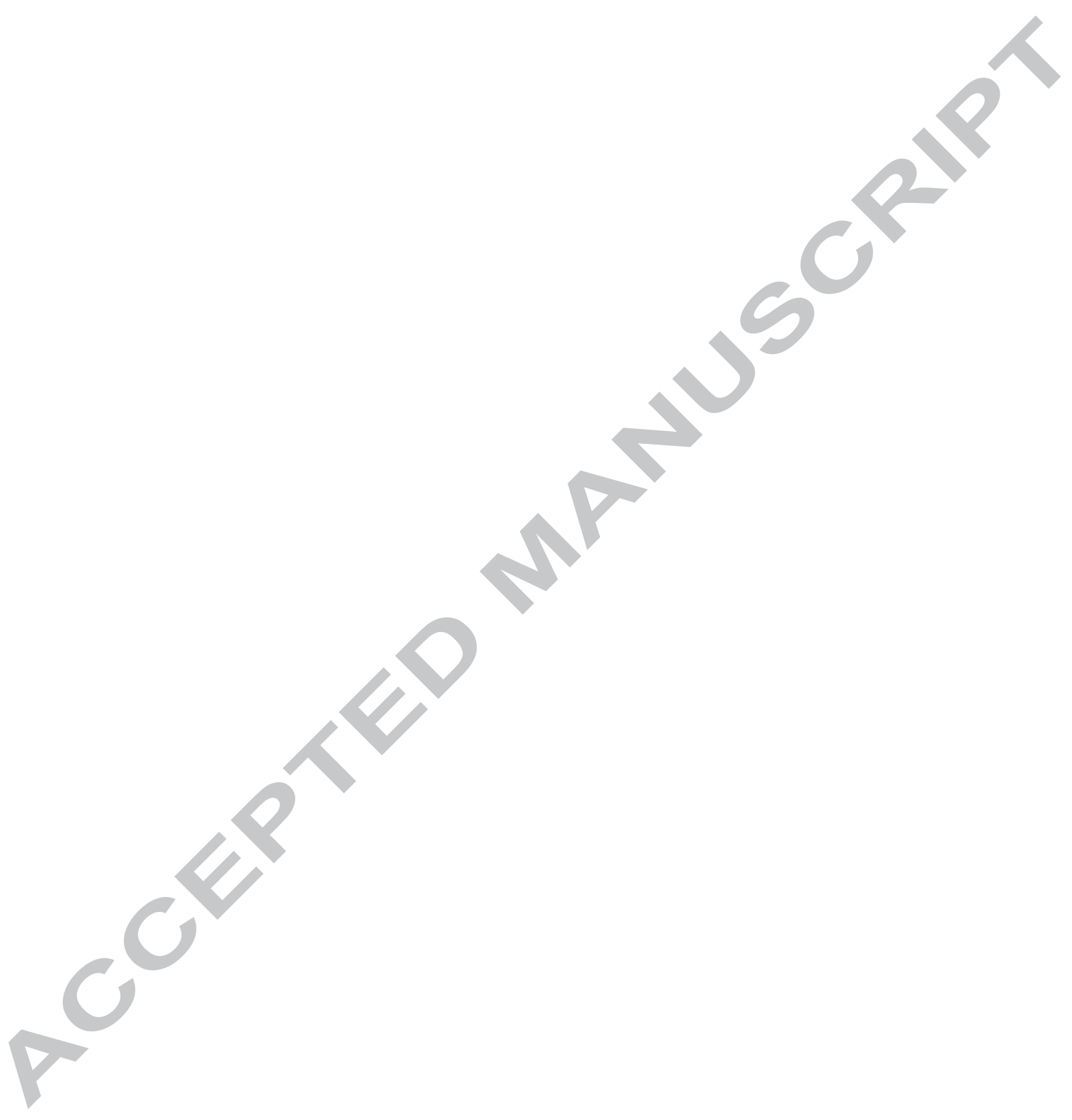

